\title{
Oral toxicity of titanium dioxide P25 at repeated dose 28-day and 90-day in rats
}

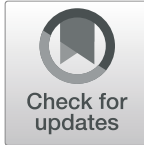

Min Beom Heo', Minjeong Kwak¹, Kyu Sup An², Hye Jin Kim², Hyeon Yeol Ryu², So Min Lee², Kyung Seuk Song², In Young Kim', Ji-Hwan Kwon ${ }^{3}$ and Tae Geol Lee ${ }^{1 *}$ (D)

\begin{abstract}
Background: Nanotechnology is indispensable to many different applications. Although nanoparticles have been widely used in, for example, cosmetics, sunscreen, food packaging, and medications, they may pose human safety risks associated with nanotoxicity. Thus, toxicity testing of nanoparticles is essential to assess the relative health risks associated with consumer exposure.

Methods: In this study, we identified the NOAEL (no observed adverse effect level) of the agglomerated/aggregated $\mathrm{TiO}_{2}$ P25 (approximately $180 \mathrm{~nm}$ ) administered at repeated doses to Sprague-Dawley (SD) rats for 28 and 90 days. Ten of the 15 animals were necropsied for toxicity evaluation after the repeated-dose 90-day study, and the remaining five animals were allowed to recover for 28 days. The agglomerated/aggregated $\mathrm{TiO}_{2}$ P25 dose levels used included $250 \mathrm{mg} \mathrm{kg}^{-1} \mathrm{~d}^{-1}$ (low), $500 \mathrm{mg} \mathrm{kg}^{-1} \mathrm{~d}^{-1}$ (medium), and $1000 \mathrm{mg} \mathrm{kg}^{-1} \mathrm{~d}^{-1}$ (high), and their effects were compared with those of the vehicle control. During the treatment period, the animals were observed for mortality, clinical signs (detailed daily and weekly clinical observations), functional observation battery, weekly body weight, and food and water consumption and were also subjected to ophthalmological examination and urinalysis. After termination of the repeated-dose 28-day, 90-day, and recovery studies, clinical pathology (hematology, blood coagulation time, and serum biochemistry), necropsy (organ weights and gross findings), and histopathological examinations were performed.
\end{abstract}

Results: No systemic toxicological effects were associated with the agglomerated/aggregated $\mathrm{TiO}_{2} \mathrm{P} 25$ during the repeated-dose 28-day, 90-day, and recovery studies in SD rats. Therefore, the NOAEL of the agglomerated/aggregated $\mathrm{TiO}_{2}$ P25 was identified as $1000 \mathrm{mg} \mathrm{kg}^{-1} \mathrm{~d}^{-1}$, and the substance was not detected in the target organs.

Conclusion: Subacute and subchronic oral administration of the agglomerated/aggregated $\mathrm{TiO}_{2}$ P25 was unlikely to cause side effects or toxic reactions in rats.

Keywords: $\mathrm{TiO}_{2}$ nanoparticles, Oral toxicity, NOAEL, Subchronic oral exposure

\section{Background}

Human exposure to nanoparticles is increasing as these materials are used in numerous applications and commercial products. Given their small size, nanoparticles can penetrate tissues and cells, inducing toxic effects. Currently, $\mathrm{TiO}_{2}$ is one of the most frequently used nanomaterials. In particular,

\footnotetext{
* Correspondence: tglee@kriss.re.kr

${ }^{1}$ Center for Nano-Bio Measurement, Industrial Metrology, Korea Research Institute of Standards and Science (KRISS), Yuseong-Gu, Daejeon, Republic of Korea

Full list of author information is available at the end of the article
}

micro- or nanoscale $\mathrm{TiO}_{2}$ has been widely used commercially in cosmetics and skin care products, paints, plastics, paper, toothpicks, and other products $[1,2]$. Nanoscale $\mathrm{TiO}_{2}$ represents less than $2 \%$ of total consumption and presents physical properties different from microscale $\mathrm{TiO}_{2}$. For example, nanoscale $\mathrm{TiO}_{2}$ is an efficient photocatalyst used in products such as dye-sensitized solar cells and UV protection agents. Pigment-grade $\mathrm{TiO}_{2}$, which accounts for more than 98\% of total consumption, has a bright white color, and is often used to enhance the appearance of food [3]. E171 
(food-grade $\mathrm{TiO}_{2}$ ), used as food additive, does not have a surface coating and may include some nanoparticles resulting from the grinding process, a conventional physical treatment. The United States Food and Drug Administration (FDA) approved pigment-grade $\mathrm{TiO}_{2}$ as a human food coloring agent in 1966 with the stipulation that the $\mathrm{TiO}_{2}$ levels are lower than $1 \%$ of the food weight [4]. According to a recent EFSA opinion article, six different brands of E171 containing different percentages of nanoparticles are used in food in the EU. The panel proposed changes to the current specifications, referring that E171 should have a minimal external dimension of $100 \mathrm{~nm}$, equivalent to less than $50 \%$ of the number of constituent particles with a median minimal external dimension below $100 \mathrm{~nm}$ [5].

A number of recent studies have characterized the mammalian toxicity of $\mathrm{TiO}_{2}$. In particular, absorbed $\mathrm{TiO}_{2}$ nanoparticles were found to be toxic to various organs because they induce oxidative stress [6, 7]. Furthermore, other research studies have also found that $\mathrm{TiO}_{2}$ nanoparticles are distributed to the major organs after inhalation [8], oral ingestion [9], and dermal penetration [10] and may translocate to systemic organs from the lung and gastrointestinal tract (GIT) [11]. Another example is that rats exposed to high levels of fine $\mathrm{TiO}_{2}$ particles by inhalation for two years developed lung tumors [12]. Based on such findings, $\mathrm{TiO}_{2}$ nanoparticles were categorized by the International Agency for Research on Cancer (IARC) as a Group 2B carcinogen (possibly carcinogenic to humans) [13]. Nevertheless, there have also been studies reporting low toxicity of $\mathrm{TiO}_{2}$. Specifically, some reports have shown that oral ingestion of $\mathrm{TiO}_{2}$ allows it to pass through the body unabsorbed because of particle agglomeration in the GIT [14, 15].

$\mathrm{TiO}_{2} \mathrm{P} 25$, which is covered in this paper, is crystallized at an 80:20 ratio of anatase and rutile and has excellent photocatalytic function without surface coating, so it is generally used as a catalyst. Many toxicity studies on $\mathrm{TiO}_{2}$ P25 have focused on inhalation and skin exposure, but studies on oral exposure have been not been reported. Therefore, the aim of the present study was to evaluate the toxicity of the agglomerated/aggregated $\mathrm{TiO}_{2}$ P25 in rats following subchronic oral exposure. The results of two independent studies are condensed in this report and include repeated-dose 28-day and 90-day oral toxicity studies and a 28 -day recovery study in rats.

\section{Results}

\section{Characterization of $\mathrm{TiO}_{2}$ nanoparticles}

The particle size distribution of the nanoparticle suspension was determined by dynamic light scattering (DLS). After dispersing the nanoparticles in $5 \mathrm{mM}$ sodium phosphate buffer, the size ranges of the agglomerated/aggregated $\mathrm{TiO}_{2}$ P25 were $187.3 \pm 54.04 \mathrm{~nm}$ (intensity), $188.7 \pm$ $67.97 \mathrm{~nm}$ (volume), and $142.9 \pm 43.97 \mathrm{~nm}$ (number), with a polydispersity index of 0.22 (Fig. 1). The particle sizes were also confirmed using transmission electron microscopy (TEM) and are in agreement with those obtained by DLS (Fig. 2).

Determination of the repeated 28-day oral dose range of $\mathrm{TiO}_{2}$ We evaluated the no observed adverse effect level (NOAEL) for the repeated-dose oral toxicity of agglomerated/aggregated $\mathrm{TiO}_{2} \mathrm{P} 25$ by administering the substance to SD rats for 28 days and determining the dose levels in a repeated-dose oral toxicity 90 -day study. No mortality or abnormal clinical signs were detected during the experimental period (data not shown). There were no statistically significant differences between the treatment and vehicle control groups in terms of body weight (Fig. 3a) or food and water consumption (Fig. 3b and c) of the male and female rats during the experimental period. The hematology results (Table 1) reveled the following changes relative to the vehicle control group: lower LY counts for the female $250 \mathrm{mg} \mathrm{kg}^{-1}, 500$ $\mathrm{mg} \mathrm{kg}{ }^{-1}$, and $1000 \mathrm{mg} \mathrm{kg}^{-1}$ dosing groups $(P<0.05)$ and higher $\mathrm{MCV}$ in the female $250 \mathrm{mg} \mathrm{kg}^{-1}$ dosing group $(P<0.05)$. Nevertheless, these differences did not indicate a significant dose-response relationship. Based on hematologic historical data accumulated in our laboratory on 10-week-old female rats, the range of $\mathrm{WBC}$ and $\mathrm{LY}$ ranged from 2.79 to $9.33 \mathrm{~K} / \mu \mathrm{L}$ and 2.17 to $8.15 \mathrm{~K} / \mu \mathrm{L}$ (95\% confidence interval range). WBC and LY values of all test substance groups fall within the normal range. As exceptionally high values in the control group were measured continuously, the values of the test substance group decrease relatively. As for the serum biochemistry results (Table 2), comparatively high $\mathrm{Cl}$ levels were observed in the female $500 \mathrm{mg} \mathrm{kg}^{-1}$ dosing group $(P<$ 0.01 ), but this difference was determined to be unrelated to the treatment because no dose-response relationship was detected. No ocular abnormalities were detected in any of the animals (data not shown). Urinalysis indicated significant differences among the male rats in terms of SG level $(P<0.05)$ (Table S1). However, these discrepancies were not attributed to the treatment because no distinct dose-response relationship was found.

There were no abnormal gross findings in any of the animals at necropsy (Table S2). In terms of organ weights (Table S3), the right adrenal glands were relatively lighter in the male dosing groups $(P<0.05)$ (absolute weights for $250 \mathrm{mg} \mathrm{kg}^{-1}$ and $1000 \mathrm{mg} \mathrm{kg}^{-1}$ and relative weights for $250 \mathrm{mg} \mathrm{kg}^{-1}, 500 \mathrm{mg} \mathrm{kg}^{-1}$, and $1000 \mathrm{mg} \mathrm{kg}^{-1}$ ). On the other hand, no substantial dose-response relationship or correlation between weight changes in bilateral organs were identified. Moreover, all measurements fell within the normal ranges. The increase in absolute liver weight of the female $250 \mathrm{mg} \mathrm{kg}^{-1}$ group $(P<0.05)$ did not present 
Size Distribution by Intensity

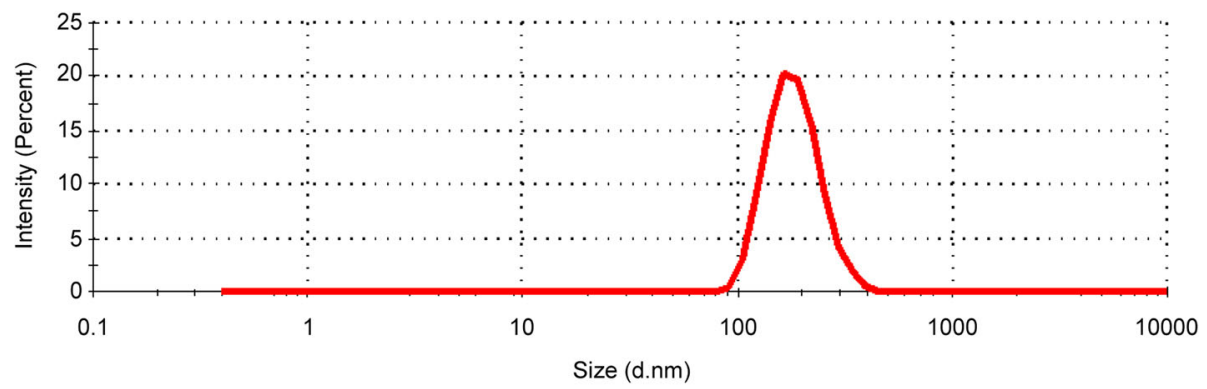

Size Distribution by Volume

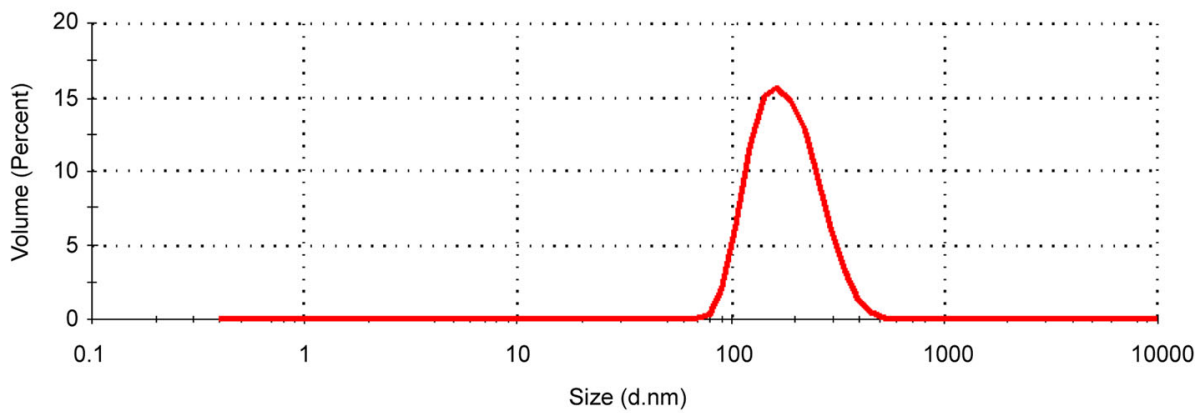

Size Distribution by Number

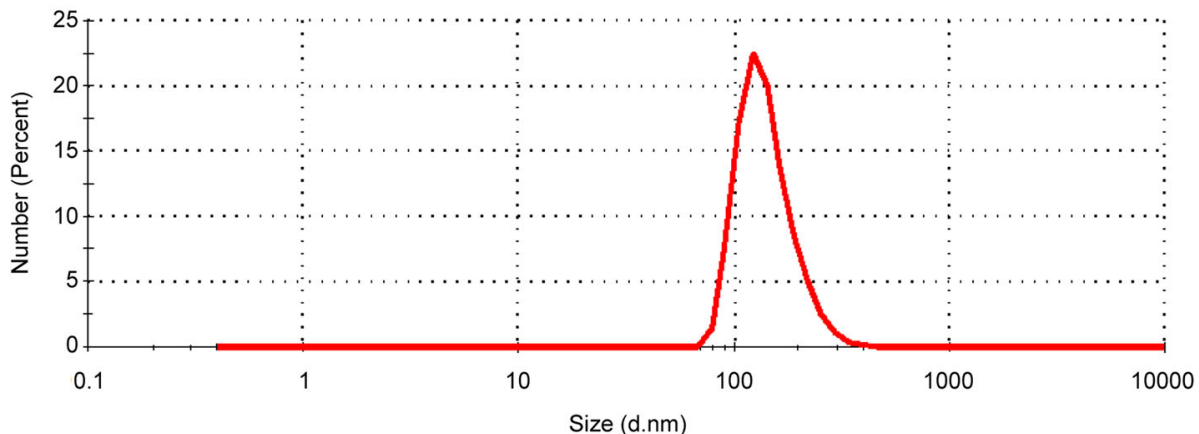

Fig. 1 Hydrodynamic diameter distribution of the agglomerated/aggregated $\mathrm{TiO}_{2} \mathrm{P} 25$ using dynamic light scattering (DLS) characterization

an evident dose-response relationship, and these changes were not attributable to the test substance.

In summary, there were no observed systemic toxicological effects associated with the agglomerated/aggregated $\mathrm{TiO}_{2}$ P25 in the repeated-dose 28-day oral toxicity study on $\mathrm{SD}$ rats under the experimental conditions used. Therefore, a NOAEL for the agglomerated/aggregated $\mathrm{TiO}_{2}$ P25 of $1000 \mathrm{mg} \mathrm{kg}^{-1}$ was identified, and a maximum dose of $1000 \mathrm{mg} \mathrm{kg}^{-1} \mathrm{~d}^{-1}$ was considered acceptable for the repeated-dose 90-day oral toxicity study.

\section{Repeated-dose 90-day oral toxicity and 28-day recovery studies of $\mathrm{TiO}_{2}$}

We evaluated the NOAEL for repeated-dose oral toxicity of agglomerated/aggregated $\mathrm{TiO}_{2}$ P25 by administering the substance to SD rats for 90 days. At $24 \mathrm{~h}$ after the last treatment, a recovery study (5 animals in each group) with a non-dose period of 28 days was performed to confirm the persistence of toxicity without treatment. No mortality or abnormal clinical signs were detected in any of the treatment groups during the exposure and recovery periods (data not shown). Detailed clinical observations disclosed significant differences among the groups in terms of male defecation and female urination frequency (Table S4). However, these changes were temporary, and alterations in the excretion rate are common even under normal conditions with no specific fecal or urinary abnormalities. Therefore, these changes were not ascribed to the administration of the test substance. In the functional observation battery, no changes related to 


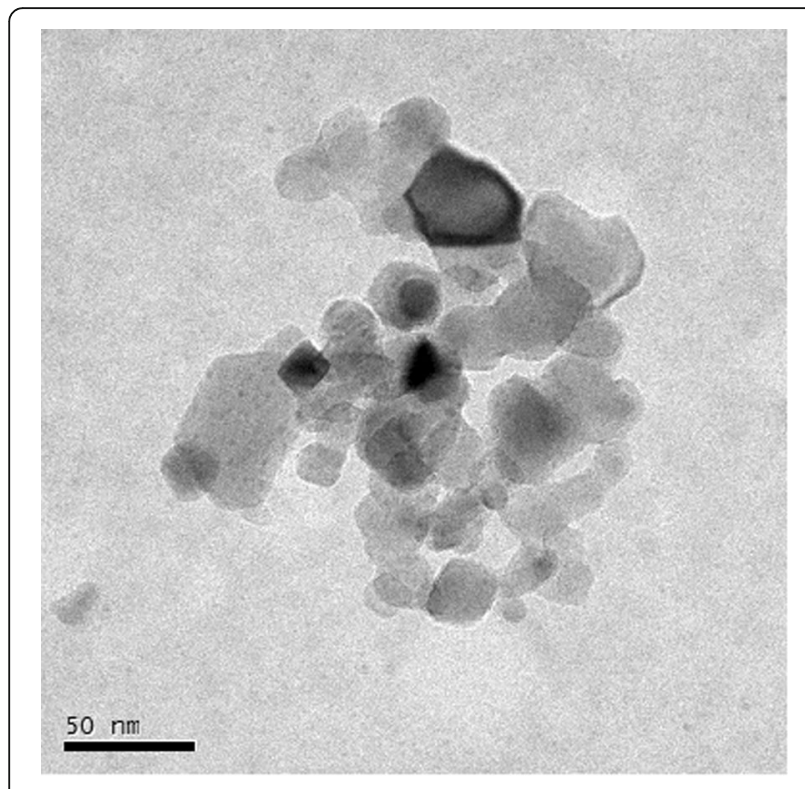

Fig. 2 Transmission electron microscopy (TEM) image of the agglomerated/aggregated $\mathrm{TiO}_{2}$ P25

the agglomerated/aggregated $\mathrm{TiO}_{2}$ P25 were detected for sensorimotor responses, spontaneous motor activity, or grip strength in any of the treated groups (data not shown). There were no statistically significant differences among the vehicle control and dosing groups in terms of body weight during the study period (Fig. 4a). Compared to that observed in the vehicle control group, food consumption decreased in the male $500 \mathrm{mg} \mathrm{kg}^{-1} \mathrm{~d}^{-1}$ dosing group at week $8(P<0.05)$ (Fig. $4 \mathrm{~b})$, and water consumption declined in the male $1000 \mathrm{mg} \mathrm{kg}^{-1} \mathrm{~d}^{-1}$ group of the recovery study at week $17(P<0.05)$ (Fig. $4 c)$. However, these discrepancies were not associated with the test substance because no dose-response correlation was found, and the alterations were either temporary or independent of subsequent related changes. No ocular abnormalities were detected in any of the animals (data not shown). The urinalysis, urine sediment test, and urine volume measurements presented with no significant differences among all treated groups (data not shown). In terms of hematology (Table 3), the PMN (neutrophil) levels were lower in the female $500 \mathrm{mg} \mathrm{kg}^{-1} \mathrm{~d}^{-1}$ dosing group than in the vehicle control group $(P<0.05)$. The PMNP (\% neutrophils) were lower and the LYP (\% lymphocyte) were higher in the female $250 \mathrm{mg} \mathrm{kg}^{-1} \mathrm{~d}^{-1}$, $500 \mathrm{mg} \mathrm{kg}^{-1} \mathrm{~d}^{-1}$, and $1000 \mathrm{mg} \mathrm{kg}^{-1} \mathrm{~d}^{-1}$ dosing groups than in the vehicle control group $(P<0.01)$. Nevertheless, no substantial dose-response or correlation between males and females were found. Moreover, these variations did not persist in the recovery study. Therefore, the observed changes were not associated with the administration of the agglomerated/ aggregated $\mathrm{TiO}_{2}$ P25.

In the blood coagulation test (data not shown) and serum biochemistry (Table 4), there were no statistically significant differences between the vehicle control and dosing groups in the 90-day treatment and recovery studies, although relatively lower BUN (blood urea

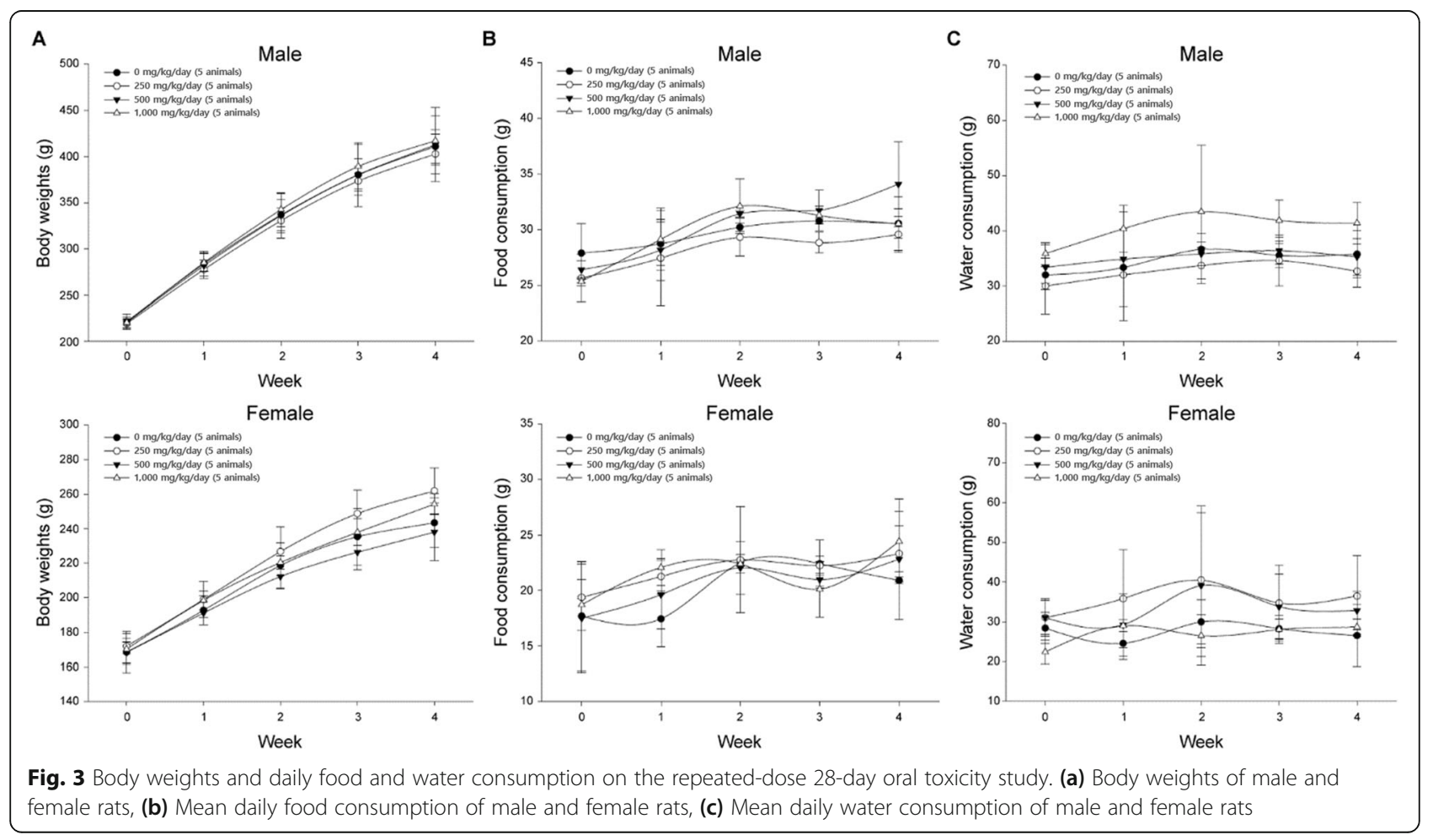




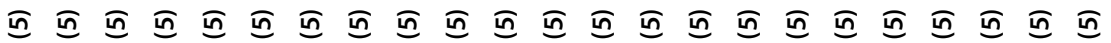

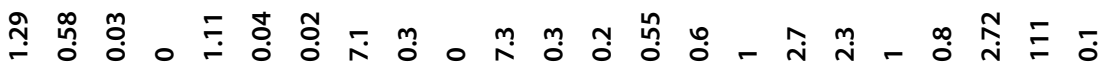

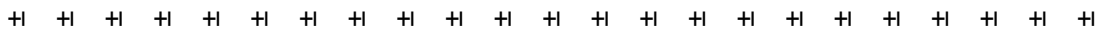

莺

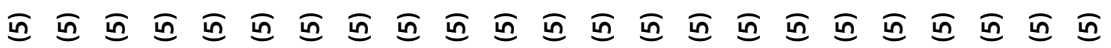

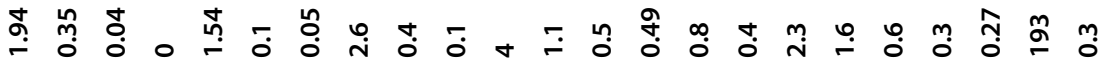

$\begin{array}{llllllllllllllllllllllll}4 & +1 & +1 & +1 & +1 & +1 & +1 & +1 & +1 & +1 & +1 & +1 & +1 & +1 & +1 & +1 & +1 & +1 & +1 & +1 & +1 & +1 & +1\end{array}$

产

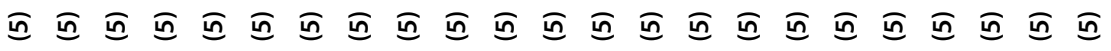

苗

$\begin{array}{llllllllllllllllllllllllll}1 & +1 & +1 & +1 & +1 & +1 & +1 & +1 & +1 & +1 & +1 & +1 & +1 & +1 & +1 & +1 & +1 & +1 & +1 & +1 & +1 & +1 & +1\end{array}$

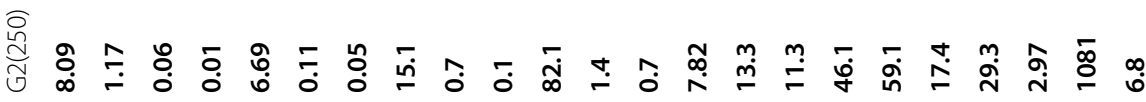

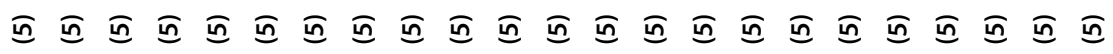

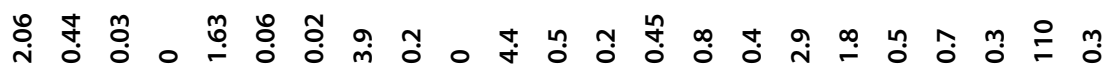

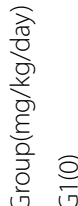

$+1+$

$\wedge=\hat{\circ}$

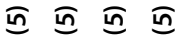

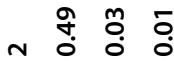

$+1+1+1$

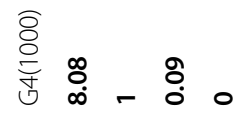

๓ᄄ

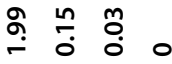

$+1+1+1+$

曽 ถู

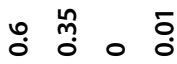
$+1+1+1+1$

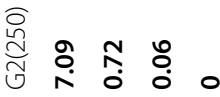
ถู

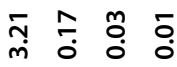
$+1+1+1+1$

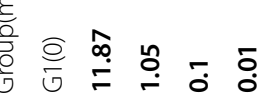




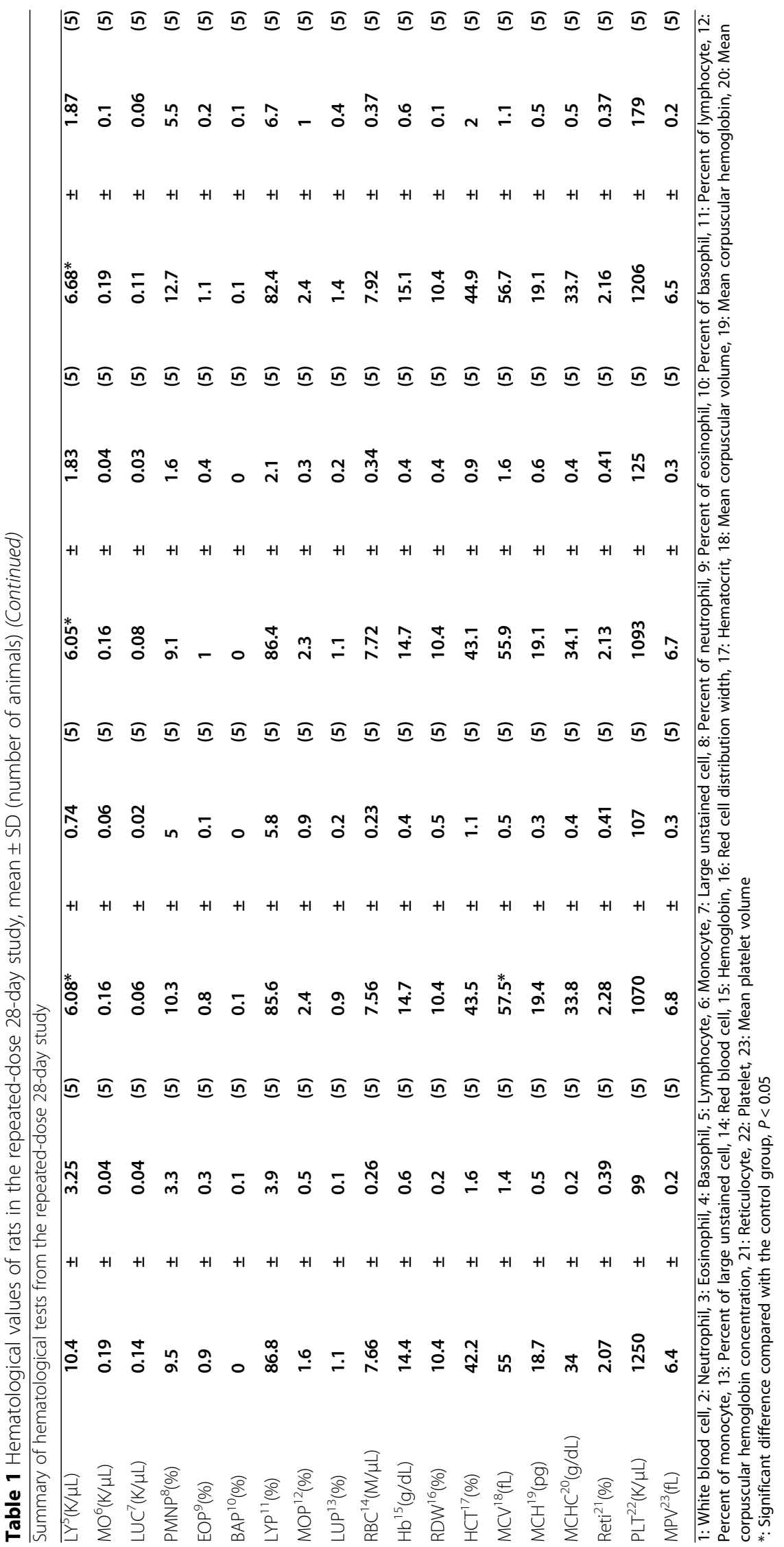




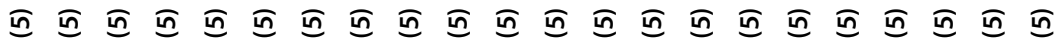
స

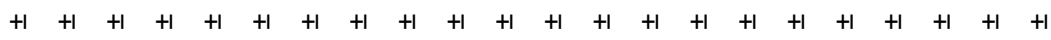

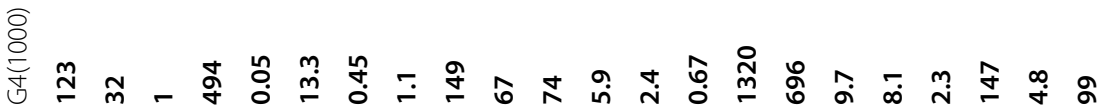

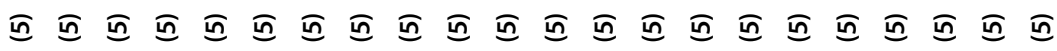

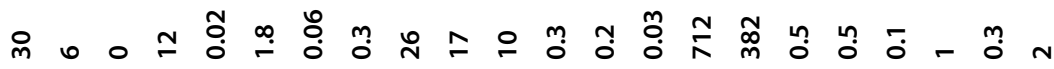

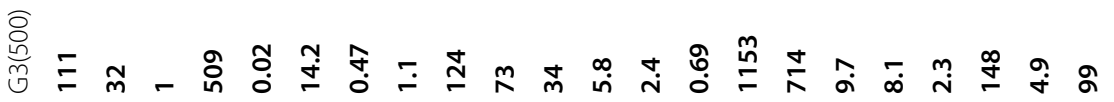

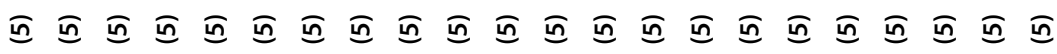

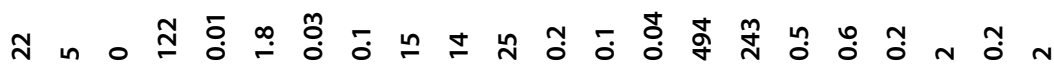

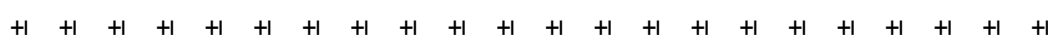

峁

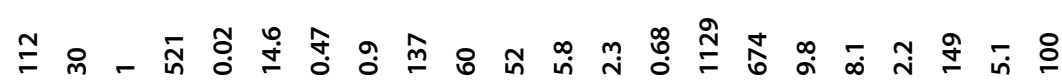

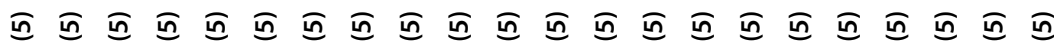

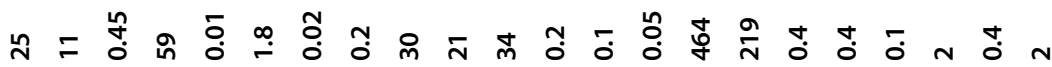

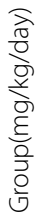
인 $\frac{0}{5}$ 象亲

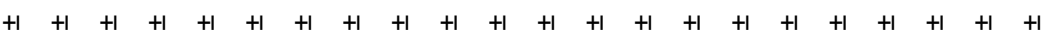
$\stackrel{\circ}{=} \stackrel{\infty}{\circ}$

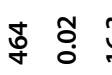

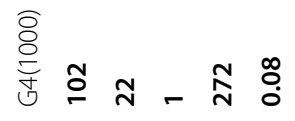
तn $\sqrt{n} \sqrt{n} \sqrt{n}$ $\stackrel{n}{\sim} \circ$ \&

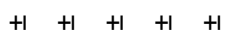

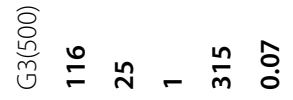
$\sqrt{n} \sqrt{n} \sqrt{n}$

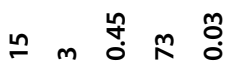

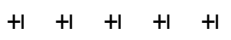
兽 $\sqrt[n]{n} \sqrt{n} \sqrt{n}$ $m m o$ in $\bar{o}_{0}$

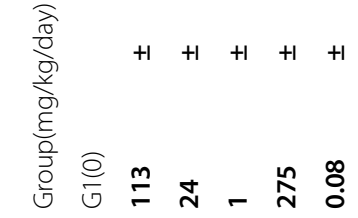

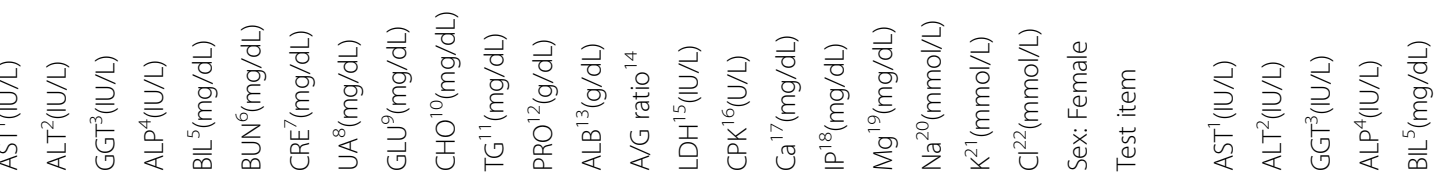


Heo et al. Particle and Fibre Toxicology

(2020) 17:34

Page 8 of 22

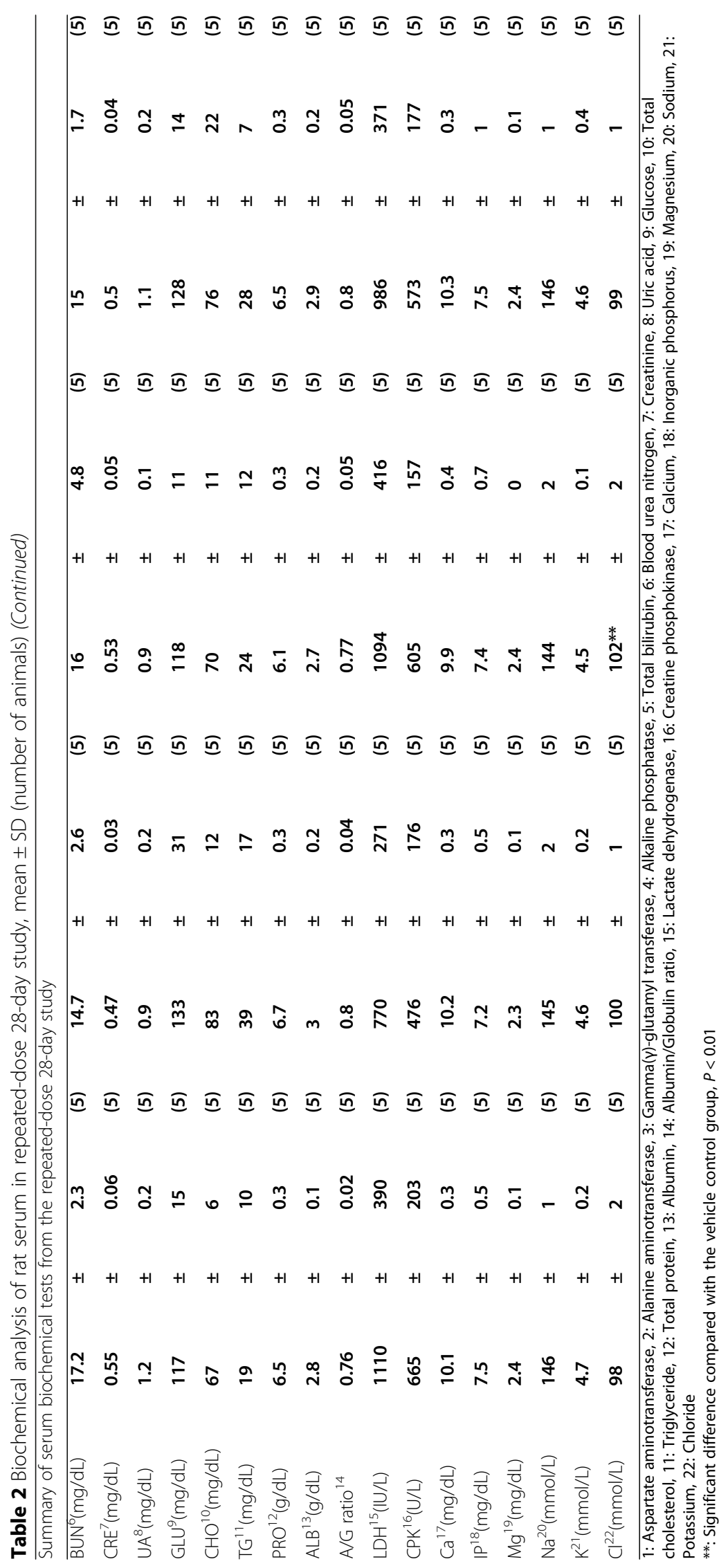



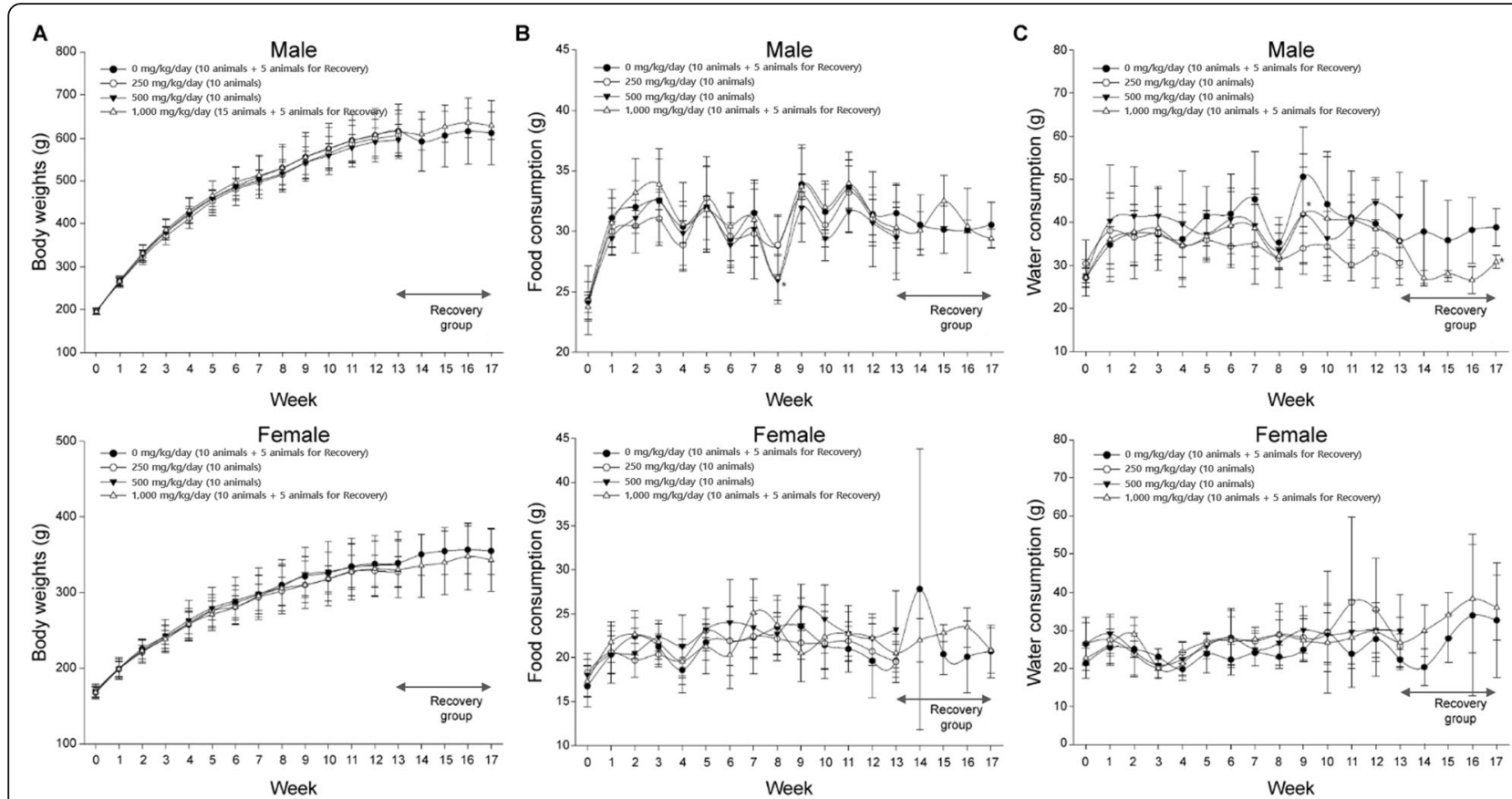

Fig. 4 Body weights and daily food and water consumption on the repeated-dose 90-day oral toxicity study. (a) Body weights of male and female rats, (b) Mean daily food consumption of male and female rats, (c) Mean daily water consumption of male and female rats

nitrogen) levels were observed in the female $1000 \mathrm{mg} \mathrm{kg}^{-1}$ $\mathrm{d}^{-1}$ group of the 90 -day treatment study $(P<0.05)$. However, the difference was minor compared to that of the vehicle control group, presenting no clinical significance. In the recovery study, the $\mathrm{Na}$ levels in the male $1000 \mathrm{mg} \mathrm{kg}^{-1}$ $\mathrm{d}^{-1}$ dosing group were lower than those of the vehicle control group $(P<0.05)$. However, the reduced values still fit within the normal range, thus considered unrelated to the test substance.

There were no abnormal gross findings in any of the animals in the 90-day treatment and recovery studies at necropsy (Table S5). For the 90-day treatment study, there were no significant differences in absolute organ weight between the vehicle control and treated groups (Table S6). Higher absolute pituitary weights were measured in the male $1000 \mathrm{mg} \mathrm{kg}^{-1} \mathrm{~d}^{-1}$ group of the recovery study $(P<0.05)$, lower absolute uterine weights were determined in the female $1000 \mathrm{mg} \mathrm{kg}^{-1} \mathrm{~d}^{-1}$ group of the recovery study $(P<0.05)$, and higher relative liver weights were found in the female $1000 \mathrm{mg} \mathrm{kg}^{-1} \mathrm{~d}^{-1}$ group of the recovery study than in the vehicle control group $(P<0.05)$ (Table S7). As these alterations were intermittent and restricted to the recovery study, they were not related to the agglomerated/aggregated $\mathrm{TiO}_{2}$ P25. The gross and histopathological findings revealed no abnormalities at necropsy. However, the histopathological examination (Table 5) disclosed lesions in the vehicle control and the $1000 \mathrm{mg} \mathrm{kg}^{-1} \mathrm{~d}^{-1}$ groups of both sexes. These included cysts or hyaline droplets on the inner stripe in the kidney, focal tubular degeneration or regeneration/degeneration and mononuclear cell infiltration to the interstitium of the kidney cortex, unilateral pyelitis, ectopic thymus or ultimobranchial cysts in the thymus, cardiomyopathy, and focal/multifocal inflammatory cell infiltration to the bronchiolo-alveoli. Nevertheless, the lesions observed in the lungs were sporadic and their frequency of occurrence did not differ significantly from that of the vehicle control group. Similarly, the occurrences of other lesions were isolated and spontaneous. For this reason, they were not considered to be associated with the agglomerated/aggregated $\mathrm{TiO}_{2} \mathrm{P} 25$.

Therefore, this study clearly showed that even moderately prolonged exposure to agglomerated/aggregated $\mathrm{TiO}_{2}$ P25 (approximately $180 \mathrm{~nm}$ ) via oral ingestion is highly unlikely to induce adverse effects or toxic reactions in rodents. Table 6 summarizes the data on the significant differences.

\section{Discussion}

Concerns about the potential risks of nanoscience and nanotechnology to human health are growing as the use of nano-sized materials in consumer products increase. $\mathrm{TiO}_{2}$ is one of the most used nanomaterials currently, and several reports have been published on the acute and subchronic oral toxicity of $\mathrm{TiO}_{2}$. However, based on previous studies and on our results, it is unclear whether $\mathrm{TiO}_{2}$ is toxic. 


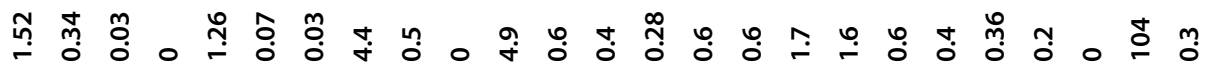

$\varsubsetneqq \stackrel{m}{0}$

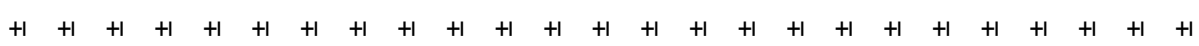

$+1+1$

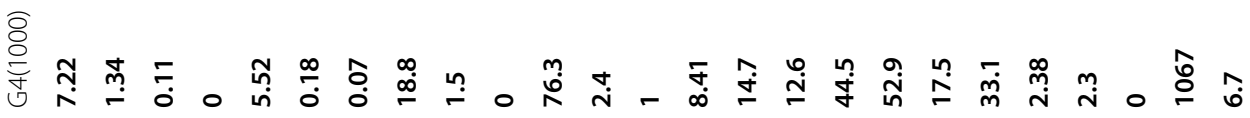

客 $+\frac{0}{0}$

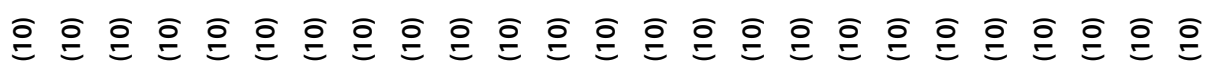

$\stackrel{\bar{g}}{\underline{g}}$

鱼 导

$\stackrel{m}{\stackrel{m}{0}} \stackrel{\infty}{\circ}$

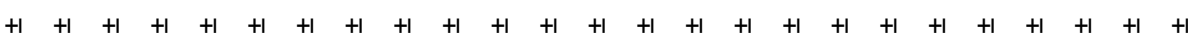

$+1$

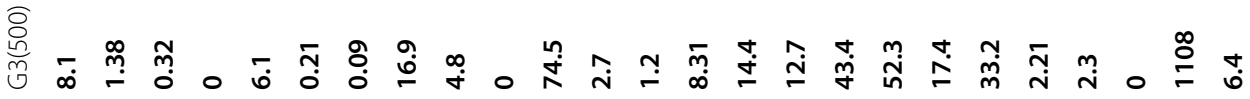

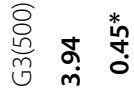

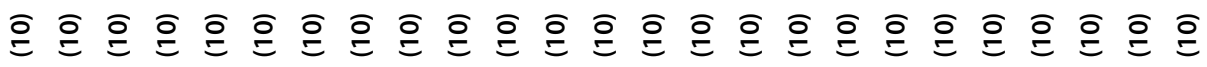

$\stackrel{\bar{\rho}}{\underline{\sigma}}$

市

กุุ จฺุ

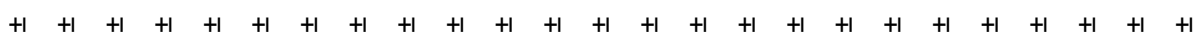

$+1+1$

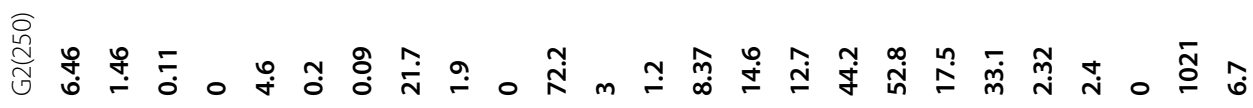

离约

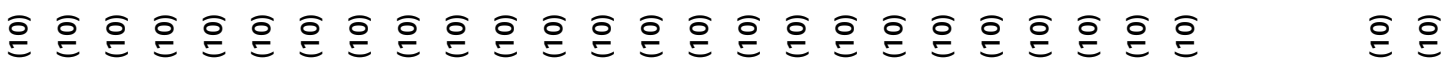

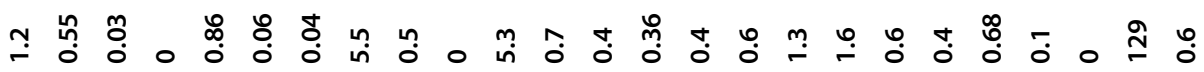

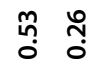




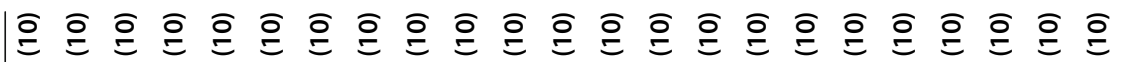

ஜㅇ 0 o

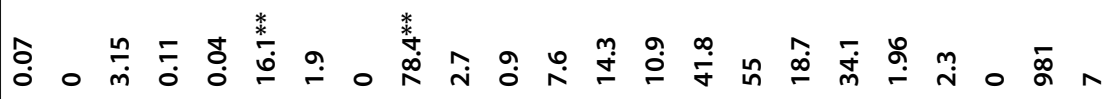

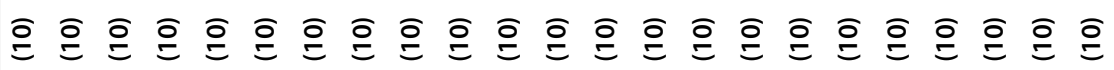

ஜㅇㅇ 0 융

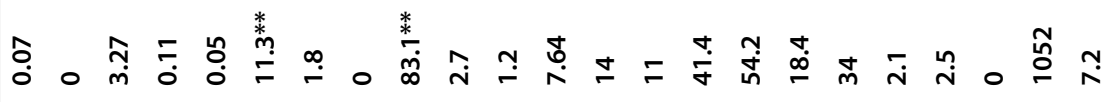

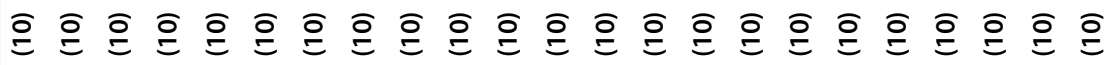

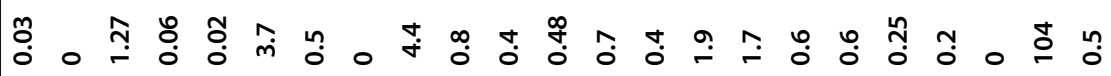

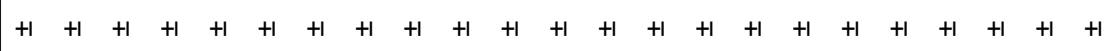

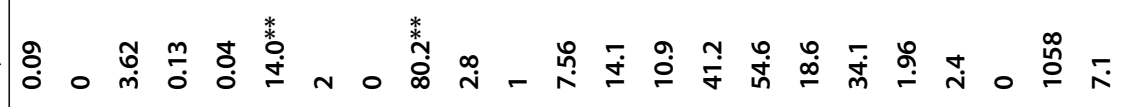

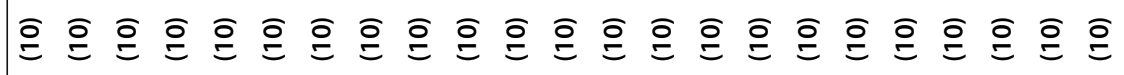

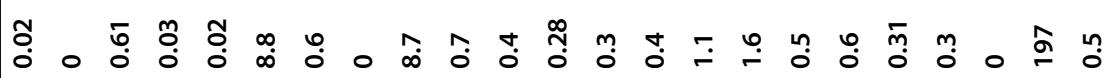
\&

产 


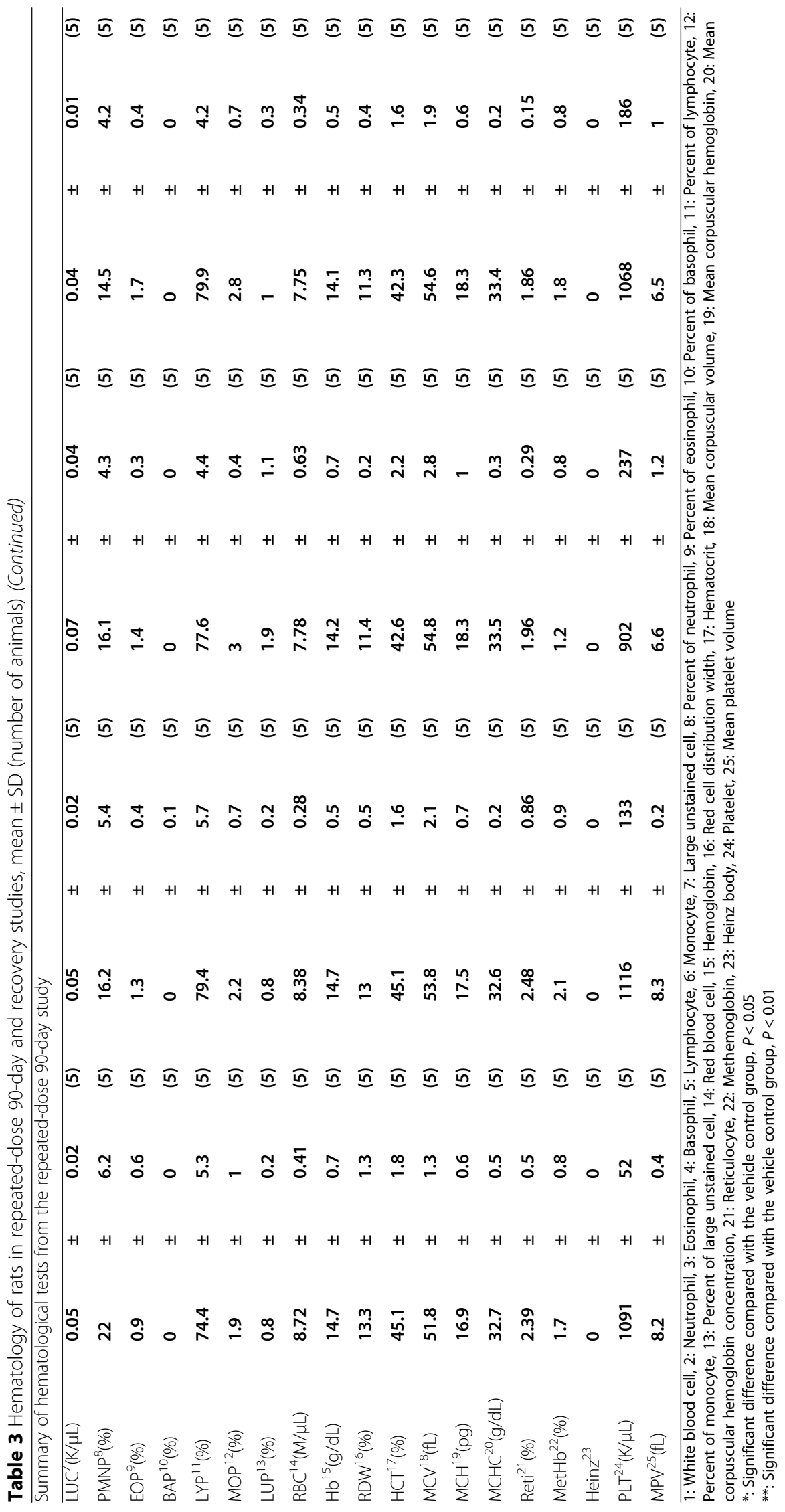




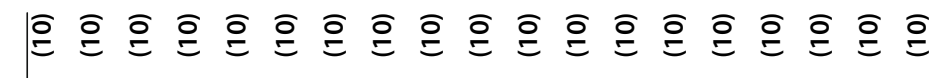

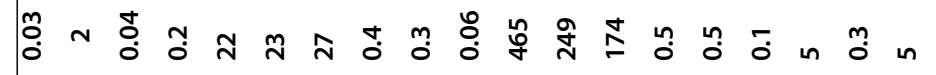

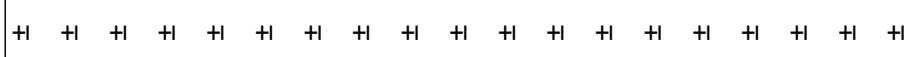

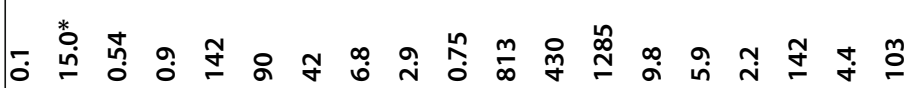

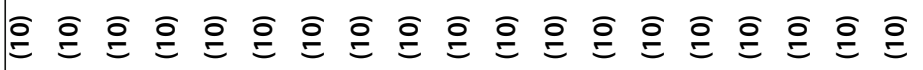

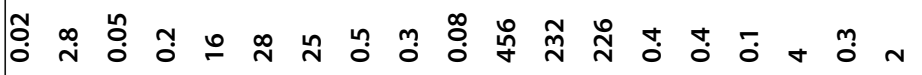

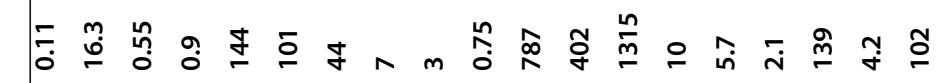

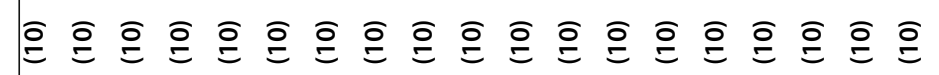

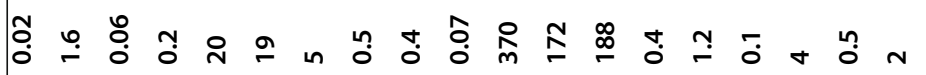

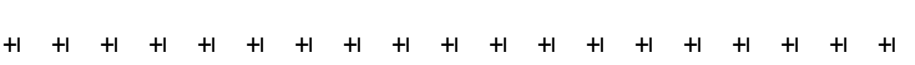
恖 在

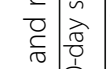

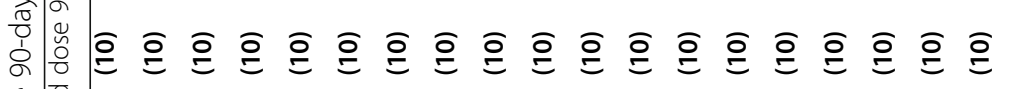

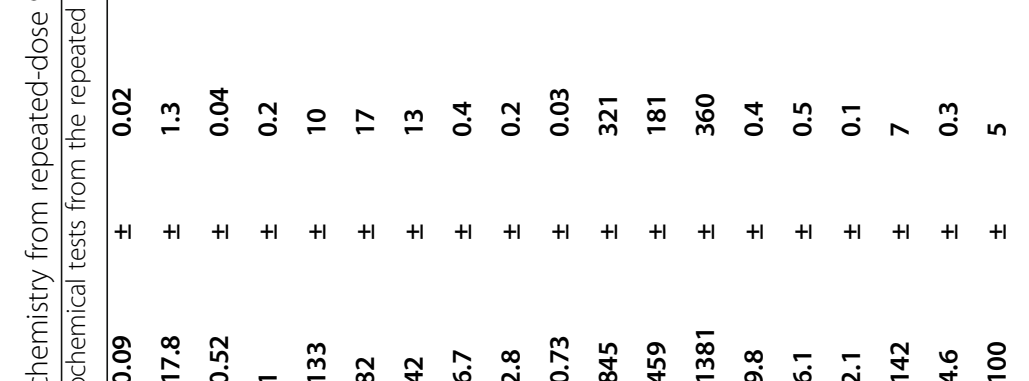
崩

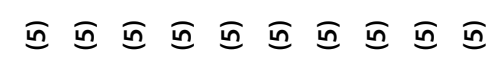

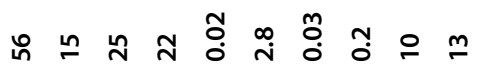
$\begin{array}{llllllllllll}n & +1 & +1 & +1 & +1 & +1 & +1 & +1 & +1 & +1\end{array}$

\section{ఠิ}

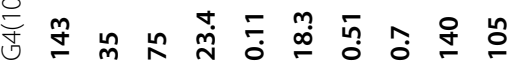

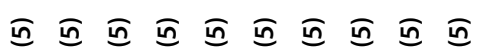

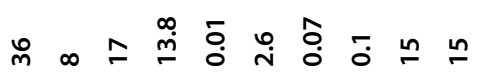

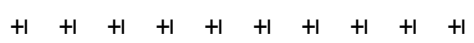

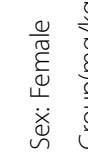

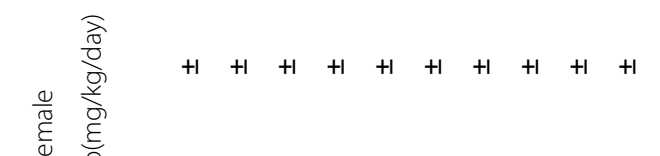

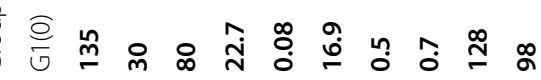

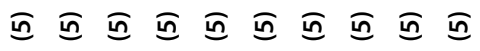

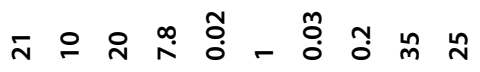
$\begin{array}{lllllllllll}1 & +1 & +1 & +1 & +1 & +1 & +1 & +1 & +1 & +1\end{array}$

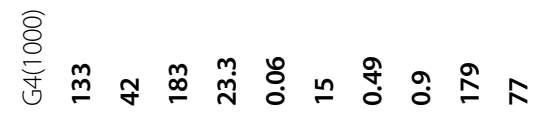

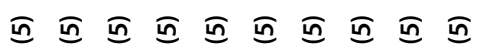

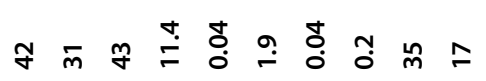

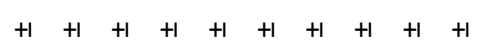
$\frac{0}{2}$ हो

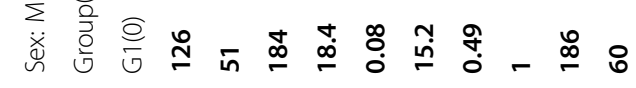

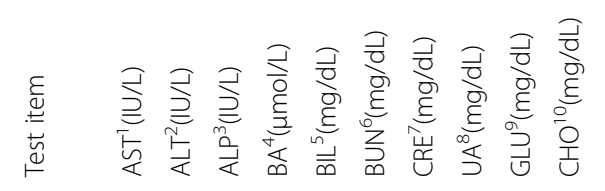




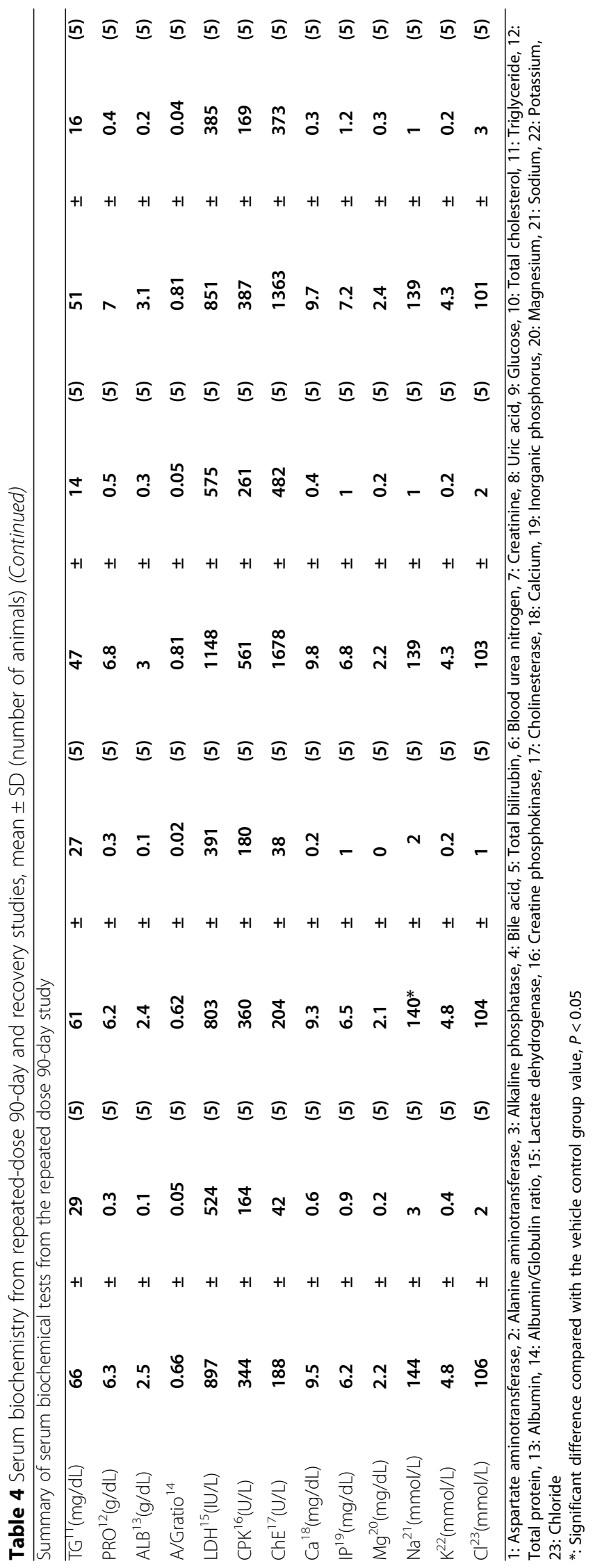


Table 5 Histopathological findings of male and female rats from the repeated-dose 90-day study and recovery study

\begin{tabular}{|c|c|c|c|c|c|c|}
\hline \multicolumn{7}{|c|}{ Summary of histopathological findings from the repeated-dose 90-day study } \\
\hline \multicolumn{7}{|l|}{ Sex: Male } \\
\hline \multirow[t]{3}{*}{ Organs } & \multirow[t]{3}{*}{ Signs } & & \multicolumn{4}{|c|}{ Group(mg/kg/day) } \\
\hline & & & \multicolumn{2}{|l|}{ G1(0) } & \multicolumn{2}{|c|}{ G4(1000) } \\
\hline & & & N & $\%$ & N & $\%$ \\
\hline Liver & No remarkable lesions & & $10 / 10$ & 100 & $10 / 10$ & 100 \\
\hline \multirow[t]{5}{*}{ Kidney } & No remarkable lesions & & $9 / 10$ & 90 & $9 / 10$ & 90 \\
\hline & Remarkable lesions & & $1 / 10$ & 10 & $1 / 10$ & 10 \\
\hline & - Cyst, inner stripe & + & $1 / 10$ & 10 & $0 / 10$ & 0 \\
\hline & - Degeneration, tubular, focal, cortex & \pm & $1 / 10$ & 10 & $0 / 10$ & 0 \\
\hline & - Pyelitis, unilateral & ++ & $0 / 10$ & 0 & $1 / 10$ & 10 \\
\hline Adrenal gl. & No remarkable lesions & & $10 / 10$ & 100 & $10 / 10$ & 100 \\
\hline Urinary bladder & No remarkable lesions & & $10 / 10$ & 100 & $10 / 10$ & 100 \\
\hline Spleen & No remarkable lesions & & $10 / 10$ & 100 & $10 / 10$ & 100 \\
\hline Pancreas & No remarkable lesions & & $10 / 10$ & 100 & $10 / 10$ & 100 \\
\hline Thymus & No remarkable lesions & & $10 / 10$ & 100 & $10 / 10$ & 100 \\
\hline \multirow[t]{3}{*}{ Thyroid } & No remarkable lesions & & $9 / 10$ & 90 & $9 / 10$ & 90 \\
\hline & Remarkable lesions & & $1 / 10$ & 10 & $1 / 10$ & 10 \\
\hline & - Ectopic thymus & $\sqrt{ }$ & $1 / 10$ & 10 & $1 / 10$ & 10 \\
\hline Parathyroid & No remarkable lesions & & $10 / 10$ & 100 & $10 / 10$ & 100 \\
\hline Trachea & No remarkable lesions & & $10 / 10$ & 100 & $10 / 10$ & 100 \\
\hline Esophagus & No remarkable lesions & & $10 / 10$ & 100 & $10 / 10$ & 100 \\
\hline Tongue & No remarkable lesions & & $10 / 10$ & 100 & $10 / 10$ & 100 \\
\hline \multirow[t]{3}{*}{ Lung } & No remarkable lesions & & $6 / 10$ & 60 & $7 / 10$ & 70 \\
\hline & Remarkable lesions & & $4 / 10$ & 40 & $3 / 10$ & 30 \\
\hline & - Cell infiltration, inflammatory, bronchioloalveolar & \pm & $4 / 10$ & 40 & $3 / 10$ & 30 \\
\hline \multirow[t]{3}{*}{ Heart } & No remarkable lesions & & $10 / 10$ & 100 & $9 / 10$ & 90 \\
\hline & Remarkable lesions & & $0 / 10$ & 0 & $1 / 10$ & 10 \\
\hline & - Cardiomyopathy & \pm & $0 / 10$ & 0 & $1 / 10$ & 10 \\
\hline Aorta & No remarkable lesions & & $10 / 10$ & 100 & $10 / 10$ & 100 \\
\hline Submandibular LN & No remarkable lesions & & $10 / 10$ & 100 & $10 / 10$ & 100 \\
\hline Mesenteric LN & No remarkable lesions & & $10 / 10$ & 100 & $10 / 10$ & 100 \\
\hline \multicolumn{7}{|l|}{ Sex: Female } \\
\hline \multirow[t]{3}{*}{ Organs } & \multirow[t]{3}{*}{ Signs } & & \multicolumn{4}{|c|}{ Group(mg/kg/day) } \\
\hline & & & \multicolumn{2}{|l|}{$\mathrm{G} 1(0)$} & \multicolumn{2}{|c|}{ G4(1000) } \\
\hline & & & N & $\%$ & $N$ & $\%$ \\
\hline \multirow[t]{3}{*}{ Liver } & No remarkable lesions & & $10 / 10$ & 100 & $9 / 10$ & 90 \\
\hline & Remarkable lesions & & $0 / 10$ & 0 & $1 / 10$ & 10 \\
\hline & - Necrosis, focal & + & $0 / 10$ & 0 & $1 / 10$ & 10 \\
\hline \multirow[t]{5}{*}{ Kidney } & No remarkable lesions & & $9 / 10$ & 90 & $9 / 10$ & 90 \\
\hline & Remarkable lesions & & $1 / 10$ & 10 & $1 / 10$ & 10 \\
\hline & - Cyst, inner stripe & \pm & $1 / 10$ & 10 & $0 / 10$ & 0 \\
\hline & - Cell infiltration, mononuclear, focal, cortex, interstitial & \pm & $1 / 10$ & 10 & $0 / 10$ & 0 \\
\hline & - Hyaline droplets, inner stripe & \pm & $0 / 10$ & 0 & $1 / 10$ & 10 \\
\hline Adrenal gl. & No remarkable lesions & & $10 / 10$ & 100 & $10 / 10$ & 100 \\
\hline
\end{tabular}


Table 5 Histopathological findings of male and female rats from the repeated-dose 90-day study and recovery study (Continued)

\begin{tabular}{|c|c|c|c|c|c|c|c|}
\hline \multicolumn{8}{|c|}{ Summary of histopathological findings from the repeated-dose 90-day study } \\
\hline Urinary bladder & No remarkable lesions & & $10 / 10$ & \multicolumn{2}{|l|}{100} & $10 / 10$ & 100 \\
\hline Spleen & No remarkable lesions & & $10 / 10$ & \multicolumn{2}{|l|}{100} & $10 / 10$ & 100 \\
\hline Pancreas & No remarkable lesions & & $10 / 10$ & \multicolumn{2}{|l|}{100} & $10 / 10$ & 100 \\
\hline Thymus & No remarkable lesions & & $10 / 10$ & \multicolumn{2}{|l|}{100} & $10 / 10$ & 100 \\
\hline \multirow[t]{3}{*}{ Thyroid } & No remarkable lesions & & $9 / 10$ & \multicolumn{2}{|l|}{90} & $9 / 10$ & 90 \\
\hline & Remarkable lesions & & $1 / 10$ & \multicolumn{2}{|l|}{10} & $1 / 10$ & 10 \\
\hline & - Ultimobranchial cyst & $\sqrt{ }$ & $1 / 10$ & \multicolumn{2}{|l|}{10} & $1 / 10$ & 10 \\
\hline Parathyroid & No remarkable lesions & & $9 / 10$ & \multicolumn{2}{|l|}{90} & $10 / 10$ & 100 \\
\hline Trachea & No remarkable lesions & & $10 / 10$ & \multicolumn{2}{|l|}{100} & $10 / 10$ & 100 \\
\hline Esophagus & No remarkable lesions & & $10 / 10$ & \multicolumn{2}{|l|}{100} & $10 / 10$ & 100 \\
\hline Tongue & No remarkable lesions & & $10 / 10$ & \multicolumn{2}{|l|}{100} & $10 / 10$ & 100 \\
\hline \multirow[t]{4}{*}{ Lung } & No remarkable lesions & & $8 / 10$ & \multicolumn{2}{|l|}{80} & $7 / 10$ & 70 \\
\hline & Remarkable lesions & & $2 / 10$ & \multicolumn{2}{|l|}{20} & $3 / 10$ & 30 \\
\hline & - Cell infiltration, inflammatory, bronchioloalveolar & \pm & $2 / 10$ & \multicolumn{2}{|l|}{20} & $2 / 10$ & 20 \\
\hline & & + & $0 / 10$ & \multicolumn{2}{|l|}{0} & $1 / 10$ & 10 \\
\hline \multirow[t]{3}{*}{ Heart } & No remarkable lesions & & $10 / 10$ & \multicolumn{2}{|l|}{100} & $9 / 10$ & 90 \\
\hline & Remarkable lesions & & $0 / 10$ & \multicolumn{2}{|l|}{0} & $1 / 10$ & 10 \\
\hline & - Cardiomyopathy & \pm & $0 / 10$ & \multicolumn{2}{|l|}{0} & $1 / 10$ & 10 \\
\hline Aorta & No remarkable lesions & & $10 / 10$ & \multicolumn{2}{|l|}{100} & 10/10 & 100 \\
\hline Submandibular LN & No remarkable lesions & & $10 / 10$ & 100 & & $10 / 10$ & 100 \\
\hline Mesenteric LN & No remarkable lesions & & $10 / 10$ & 100 & & $10 / 10$ & 100 \\
\hline Summary of histopa & indings from the recovery study & & & & & & \\
\hline Sex: Male & & & & & & & \\
\hline Organs & Signs & & & Grou & $\mathrm{g} / \mathrm{kg} / \mathrm{c}$ & & \\
\hline & & & & $\mathrm{G} 1(0)$ & & $\mathrm{G} 4(1000)$ & \\
\hline & & & & $N$ & $\%$ & $N$ & $\%$ \\
\hline Liver & No remarkable lesions & & & $5 / 5$ & 100 & $5 / 5$ & 100 \\
\hline Kidney & No remarkable lesions & & & $4 / 5$ & 80 & $5 / 5$ & 100 \\
\hline & Remarkable lesions & & & $1 / 5$ & 20 & $0 / 5$ & 0 \\
\hline & - Regeneration/degeneration, tubular, cortex & \pm & & $1 / 5$ & 20 & $0 / 5$ & 0 \\
\hline Adrenal gl. & No remarkable lesions & & & $5 / 5$ & 100 & $5 / 5$ & 100 \\
\hline Urinary bladder & No remarkable lesions & & & $5 / 5$ & 100 & $5 / 5$ & 100 \\
\hline Spleen & No remarkable lesions & & & $5 / 5$ & 100 & $5 / 5$ & 100 \\
\hline Pancreas & No remarkable lesions & & & $5 / 5$ & 100 & $5 / 5$ & 100 \\
\hline Thymus & No remarkable lesions & & & $5 / 5$ & 100 & $5 / 5$ & 100 \\
\hline Thyroid & No remarkable lesions & & & $5 / 5$ & 100 & $5 / 5$ & 100 \\
\hline Parathyroid & No remarkable lesions & & & $5 / 5$ & 100 & $5 / 5$ & 100 \\
\hline Trachea & No remarkable lesions & & & $5 / 5$ & 100 & $5 / 5$ & 100 \\
\hline Esophagus & No remarkable lesions & & & $5 / 5$ & 100 & $5 / 5$ & 100 \\
\hline Tongue & No remarkable lesions & & & $5 / 5$ & 100 & $5 / 5$ & 100 \\
\hline Lung & No remarkable lesions & & & $1 / 5$ & 20 & $2 / 5$ & 40 \\
\hline & Remarkable lesions & & & $4 / 5$ & 80 & $3 / 5$ & 60 \\
\hline & - Cell infiltration, inflammatory, bronchioloalveolar & \pm & & $3 / 5$ & 60 & $3 / 5$ & 60 \\
\hline & & + & & $1 / 5$ & 20 & $0 / 5$ & 0 \\
\hline
\end{tabular}


Table 5 Histopathological findings of male and female rats from the repeated-dose 90-day study and recovery study (Continued)

\begin{tabular}{|c|c|c|c|c|c|c|}
\hline \multicolumn{7}{|c|}{ Summary of histopathological findings from the repeated-dose 90-day study } \\
\hline \multirow[t]{3}{*}{ Heart } & No remarkable lesions & & $4 / 5$ & 80 & $4 / 5$ & 80 \\
\hline & Remarkable lesions & & $1 / 5$ & 20 & $1 / 5$ & 20 \\
\hline & - Cardiomyopathy & \pm & $1 / 5$ & 20 & $1 / 5$ & 20 \\
\hline Aorta & No remarkable lesions & & $5 / 5$ & 100 & $5 / 5$ & 100 \\
\hline Submandibular LN & No remarkable lesions & & $5 / 5$ & 100 & $5 / 5$ & 100 \\
\hline Mesenteric LN & No remarkable lesions & & $5 / 5$ & 100 & $5 / 5$ & 100 \\
\hline Salivary gl. submandibular & No remarkable lesions & & $5 / 5$ & 100 & $5 / 5$ & 100 \\
\hline Salivary gl. sublingual & No remarkable lesions & & $5 / 5$ & 100 & $5 / 5$ & 100 \\
\hline Salivary gl. parotid & No remarkable lesions & & $5 / 5$ & 100 & $5 / 5$ & 100 \\
\hline \multicolumn{7}{|l|}{ Sex: Female } \\
\hline \multirow[t]{3}{*}{ Organs } & \multirow[t]{3}{*}{ Signs } & & \multicolumn{4}{|c|}{ Group(mg/kg/day) } \\
\hline & & & \multicolumn{2}{|c|}{ G1(0) } & \multicolumn{2}{|c|}{ G4(1000) } \\
\hline & & & $\mathrm{N}$ & $\%$ & $\mathrm{~N}$ & $\%$ \\
\hline Liver & No remarkable lesions & & $5 / 5$ & 100 & $5 / 5$ & 100 \\
\hline Kidney & No remarkable lesions & & $5 / 5$ & 100 & $5 / 5$ & 100 \\
\hline Adrenal gl. & No remarkable lesions & & $5 / 5$ & 100 & $5 / 5$ & 100 \\
\hline Urinary bladder & No remarkable lesions & & $5 / 5$ & 100 & $5 / 5$ & 100 \\
\hline Spleen & No remarkable lesions & & $5 / 5$ & 100 & $5 / 5$ & 100 \\
\hline Pancreas & No remarkable lesions & & $5 / 5$ & 100 & $5 / 5$ & 100 \\
\hline Thymus & No remarkable lesions & & $5 / 5$ & 100 & $5 / 5$ & 100 \\
\hline Thyroid & No remarkable lesions & & $5 / 5$ & 100 & $5 / 5$ & 100 \\
\hline Parathyroid & No remarkable lesions & & $5 / 5$ & 100 & $5 / 5$ & 100 \\
\hline Trachea & No remarkable lesions & & $5 / 5$ & 100 & $5 / 5$ & 100 \\
\hline Esophagus & No remarkable lesions & & $5 / 5$ & 100 & $5 / 5$ & 100 \\
\hline Tongue & No remarkable lesions & & $5 / 5$ & 100 & $5 / 5$ & 100 \\
\hline \multirow[t]{4}{*}{ Lung } & No remarkable lesions & & $3 / 5$ & 60 & $3 / 5$ & 60 \\
\hline & Remarkable lesions & & $2 / 5$ & 40 & $2 / 5$ & 40 \\
\hline & \multirow[t]{2}{*}{ - Cell infiltration, inflammatory, bronchioloalveolar } & \pm & $1 / 5$ & 20 & $2 / 5$ & 40 \\
\hline & & + & $1 / 5$ & 20 & $0 / 5$ & 0 \\
\hline Heart & No remarkable lesions & & $5 / 5$ & 100 & $5 / 5$ & 100 \\
\hline Aorta & No remarkable lesions & & $5 / 5$ & 100 & $5 / 5$ & 100 \\
\hline Submandibular LN & No remarkable lesions & & $5 / 5$ & 100 & $5 / 5$ & 100 \\
\hline Mesenteric LN & No remarkable lesions & & $5 / 5$ & 100 & $5 / 5$ & 100 \\
\hline Salivary gl. submandibular & No remarkable lesions & & $5 / 5$ & 100 & $5 / 5$ & 100 \\
\hline Salivary gl. sublingual & No remarkable lesions & & $5 / 5$ & 100 & $5 / 5$ & 100 \\
\hline Salivary gl. parotid & No remarkable lesions & & $5 / 5$ & 100 & $5 / 5$ & 100 \\
\hline
\end{tabular}

$N$ Number of animals with the signs/Number of examined animals

\pm : minimal, +: mild, ++: moderate, $\sqrt{ }$ : present, gl. = gland, $L N=$ lymph node

In the present study, we investigated the subacute and subchronic toxicity of the agglomerated/aggregated $\mathrm{TiO}_{2}$ P25 administered orally to rats $\left(250 \mathrm{mg} \mathrm{kg}^{-1}, 500 \mathrm{mg}\right.$ $\mathrm{kg}^{-1}$, or $1000 \mathrm{mg} \mathrm{kg}^{-1}$ ) at $24 \mathrm{~h}$ intervals for 28 and 90 days; a recovery study with a non-dosing period of 28 days was also conducted to confirm the persistence of toxicity without treatment at study termination, in accordance with the Organization for Economic Cooperation and Development (OECD) 407 and 408 procedures $[16,17]$. In the case of the subchronic studies with longer exposure periods than subacute studies, a recovery phase (non-dosing period) is necessary to ascertain that the toxicities observed at the end of the dosing phase are partially or completely reversible. Additionally, as the 
physicochemistry of the nanoparticles must be evaluated as part of the toxicity test, we characterized the agglomerated/aggregated $\mathrm{TiO}_{2} \mathrm{P} 25$ by DLS and TEM. Based on a previous study, we selected $5 \mathrm{mM}$ sodium phosphate buffer ( $\mathrm{pH} \mathrm{8.0)}$ as the vehicle to obtain the most stable dispersion stability [18]. The dispersion protocol developed by the National Institute of Standards and Technology $[19,20]$ was used, and the dispersed particles were approximately $180 \mathrm{~nm}$ in size. The hydrodynamic diameters indicated that the primary $\mathrm{TiO}_{2}$ nanoparticles aggregated and agglomerated upon dispersal in the vehicle. No systemic toxicological effects were related with the agglomerated/aggregated $\mathrm{TiO}_{2} \mathrm{P} 25$ in the repeateddose 28-day and 90-day oral toxicity and 28-day recovery studies in SD rats under the experimental conditions used. Therefore, the NOAEL of the agglomerated/aggregated $\mathrm{TiO}_{2}$ P25 was identified as $1000 \mathrm{mg} \mathrm{kg}^{-1} \mathrm{~d}^{-1}$, and this test substance was not detected in the target organs.

These results are consistent with the results of previous publications. In the acute oral toxicity study of $\mathrm{TiO}_{2}$, Warheit et al. showed only low potential health risks in mammals or aquatic species acutely exposed to ultrafine $\mathrm{TiO}_{2}$ particles [21], and a fixed $5 \mathrm{~g} \mathrm{~kg}^{-1}$ body weight dose of $\mathrm{TiO}_{2}$ suspension showed no obvious acute toxicity after two weeks [9]. In the subchronic oral toxicity study, Warheit et al. reported no significant oral toxicity induced by the nanoscale component of the $\mathrm{TiO}_{2}$ test material in the 90-day study [22]; furthermore, $\mathrm{TiO}_{2}$ particles consisting of $80 \%$ anatase and $20 \%$ rutile displayed an extremely low absorption rate in the liver, spleen, kidney, and brain tissues [23].

As mentioned above, $\mathrm{TiO}_{2}$-induced toxicity was not detected after acute and subchronic oral administration, but other studies have reported the opposite. Tassinari et al. explored possible effects of short-term ( 5 days) oral exposure to anatase $\mathrm{TiO}_{2}$ nanoparticles $(0,1,2 \mathrm{mg} / \mathrm{kg}$ b.w $)$ on the reproductive and endocrine systems of rats, and reported that the Ti levels were increased in the spleen and ovaries [24]. Moreover, Dasal et al. stated that oral administration of $\mathrm{TiO}_{2}$ nanoparticles $(<100 \mathrm{~nm}$ diameter) may induce hepatic and renal toxicity in experimental rats at 14 days post-exposure [25]. Moreover, in a 90-day study on the exposure of rats to $\mathrm{TiO}_{2}$ nanoparticles (intragastric administration: $2.5,5,10 \mathrm{mg} / \mathrm{kg}$ b.w.), the authors showed spleen injury and alteration of cytokine expression [26]. Another long-term (90-day) oral toxicity study (2.5, 5, 10 $\mathrm{mg} / \mathrm{kg}$ b.w) in mice showed ovarian damage, oxidative stress, testicular lesions, and sperm malformations [27, 28 ]. Recent reports have confirmed the presence of agglomerated/aggregated $\mathrm{TiO}_{2}$ particles (85 to $720 \mathrm{~nm}$ ) in post-mortem human liver and spleen, where $24 \%$ of the particles were $100 \mathrm{~nm}$ or less in size. For these reasons, health risks associated with liver damage due to $\mathrm{TiO}_{2}$ particles cannot be excluded [29].
Similarly, millions of tons of E171, a white pigment, are used in food each year, which can have a much greater effect than P25 on the environment and on human exposure [30]. The primary particle size of E171 is $60-300 \mathrm{~nm}$, of which $10-15 \%$ is < $100 \mathrm{~nm}$ [31]. Recently, much attention has been paid to the safety of E171, with numerous articles being published on this issue. Some research groups have reported that exposure to E171 containing a mixture of micro- and nano-sized particles can induce ROS generation and DNA damage in in vitro models [32]; others have reported on changes in gene expression and impaired immune homeostasis occurred in the colons of BALB/c mice and promotion of aberrant crypt development in the rat colon after short-term oral administration [33, 34].

As the aforementioned conflicting results show, there is an ongoing debate about the safety of $\mathrm{TiO}_{2}$. Recently, France has decided to ban the use of E171, which is mainly used as a food additive, from 2020. Much of the concern is related to the unclear identification of their hazards as additives. Clearly, reliable results from welldesigned toxicology tests are necessary. We aim to perform more studies in the future to investigate subchronic oral toxicity of E171.

\section{Conclusions}

In our study, the subacute and subchronic oral toxicity of agglomerated/aggregated $\mathrm{TiO}_{2}$ P25 (approximately $180 \mathrm{~nm}$ ) were investigated in rats according to the standard procedure (OECD Guidelines, No. 407 and 408) for testing chemicals. The NOAEL of the agglomerated/aggregated $\mathrm{TiO}_{2}$ P25 was $1000 \mathrm{mg} \mathrm{kg}^{-1} \mathrm{~d}^{-1}$. Although there were significant differences in some results, they were unrelated to the test substance. Collectively, the results from our studies can contribute to future safety assessment of $\mathrm{TiO}_{2}$ materials in humans.

\section{Methods}

\section{$\mathrm{TiO}_{2}$ particles}

$\mathrm{TiO}_{2}$ nanoparticles (AEROXIDE ${ }^{\circledR} \mathrm{TiO}_{2}$ P25, KRISS CRM 301-03-001, anatase/rutile (80/20), 99.9\%; average primary particle size range $14-21 \mathrm{~nm}$ ) were purchased from Evonik Industries AG (Essen, Germany). $\mathrm{TiO}_{2}$ nanoparticles were in the form of a white hydrophilic powder without surface modification and were stored at room temperature. $\mathrm{TiO}_{2}$ nanoparticle suspensions were prepared by dispersing the particles in $5 \mathrm{mM}$ sodium phosphate buffer ( $\mathrm{pH}$ 8.0; Sigma-Aldrich Corp., St. Louis, MO, USA) followed by sonication (Branson Ultrasonics 450D; Thermo Fisher Scientific, Waltham, MA, USA) at $50 \mathrm{~W}$ for $17.5 \mathrm{~min}$ in an ice water bath to prevent the suspensions from overheating. 
Table 6 Summarized data on the significant differences in analysis results

\begin{tabular}{|c|c|c|}
\hline Period & Significant differences (vs. G1) & Results \\
\hline \multirow[t]{10}{*}{ 28-day } & - Urinalysis & \multirow{6}{*}{$\begin{array}{l}\text { - No dose-response } \\
\text { correlation } \\
\text { - Within biological } \\
\text { normal ranges } \\
\text { - Temporary or isolated } \\
\text { symptoms without } \\
\text { subsequent changes }\end{array}$} \\
\hline & - SG (male - G2, 3, 4) & \\
\hline & - Hematological values & \\
\hline & - LY (female - G2, 3, 4) $\downarrow$ & \\
\hline & - MCV (female - G2) $\uparrow$ & \\
\hline & - Serum biochemical values & \\
\hline & - Cl (female - G3) $\uparrow$ & \multirow{14}{*}{$\begin{array}{l}\rightarrow \text { No relationship with } \\
\text { the test substance }\end{array}$} \\
\hline & - Absolute organ weight & \\
\hline & $\begin{array}{l}\text { - Right adrenal glands } \\
\text { (male - } \mathrm{G} 2,4) \downarrow\end{array}$ & \\
\hline & - Livers (female - G2) $\uparrow$ & \\
\hline \multirow[t]{10}{*}{ 90-day } & $\begin{array}{l}\text { - Detailed clinical } \\
\text { observations }\end{array}$ & \\
\hline & - Defecation (male in week-4) & \\
\hline & - Urination (female in week-12) & \\
\hline & $\begin{array}{l}\text { - Food consumption (male in } \\
\text { week-8 - G3) } \downarrow\end{array}$ & \\
\hline & - Hematological values & \\
\hline & - NE (female - G3) $\downarrow$ & \\
\hline & - NEP (female - G2, 3, 4) $\downarrow$ & \\
\hline & - LYP (female - G2, 3, 4) $\uparrow$ & \\
\hline & - Serum biochemical values & \\
\hline & - BUN (female - G4) $\downarrow$ & \\
\hline \multirow{8}{*}{$\begin{array}{l}\text { Recovery } \\
\text { (for } 28 \\
\text { days) }\end{array}$} & $\begin{array}{l}\text { - Water intake (male in } \\
\text { week-17 - G4) } \downarrow\end{array}$ & \\
\hline & - Serum biochemical values & \\
\hline & - Na (male - G4) $\downarrow$ & \\
\hline & - Absolute organ weight & \\
\hline & - Pituitary glands (male - G4) $\uparrow$ & \\
\hline & - Uterus (female - G4) $\downarrow$ & \\
\hline & - Relative organ weight & \\
\hline & - Liver (female - G4) $\uparrow$ & \\
\hline
\end{tabular}

\section{Particle characterization}

The hydrodynamic diameters of the particles in $5 \mathrm{mM}$ sodium phosphate buffer were measured by DLS using a Zetasizer Nano ZS90 (Malvern Panalytical Ltd., Malvern, UK) and were confirmed by TEM using the FEI Tecnai F30, operated at an acceleration voltage of $300 \mathrm{kV}$. The $\mathrm{pH}$ value of the prepared vehicle was measured with a $\mathrm{pH}$ meter (Orion Star A210; Thermo Fisher Scientific, Waltham, MA, USA) and the $\mathrm{pH}$ range was confirmed to be 8.05-8.11.

\section{Animals}

Pathogen-free SD rats [Crl:CD(Sprague-Dawley)] were purchased from Orient Bio Inc. (Seongnam, Korea).
Healthy young adult animals (males and non-pregnant females) were acclimated and closely monitored for 6 days after arrival in the SPF animal facility area, and were randomly assigned to the control and treatment groups. Only animals with the best appearance were selected for subsequent testing. The body weights of the male and female rats were $210-232 \mathrm{~g}$ and $157-185 \mathrm{~g}$, respectively, at the time of the first administration in the repeated-dose 28-day experiment. The body weights of the male and female rats were 185-207 g and 149-183 g, respectively, at the time of the first administration in the repeated-dose 90-day experiment. Rats were housed two per cage in an environmentally controlled room at $22.9 \pm$ $0.5^{\circ} \mathrm{C}$ and relative humidity of $54.3 \pm 4.2 \%$. The room air was replaced 10-15x per hour. Lighting was set to a 12-h light/dark cycle (on at 08 h00 and off at 20 h00).

\section{Experimental design}

One hundred and forty healthy adult SD rats were used in this study (Table S8). For the repeated-dose 28-day experiment, the animals were randomly divided into four groups, each consisting of five animals per sex. For the repeated-dose 90-day experiment, the animals were randomly assigned to four groups. Each group consisted of 10-15 animals per sex. One group was administered 5 $\mathrm{mM}$ sodium phosphate buffer by gavage and served as the vehicle control group (G1). The three remaining groups received one of three agglomerated/aggregated $\mathrm{TiO}_{2}$ P25 dosages by gavage (250 mg kg ${ }^{-1} \mathrm{~d}^{-1}$ (G2), 500 $\mathrm{mg} \mathrm{kg}^{-1} \mathrm{~d}^{-1}$ (G3), and $1000 \mathrm{mg} \mathrm{kg}^{-1} \mathrm{~d}^{-1}$ (G4)). The dosing volume was $10 \mathrm{~mL} \mathrm{~kg}^{-1}$ body weight. The agglomerated/aggregated $\mathrm{TiO}_{2} \quad$ P25 were administered every morning for either 28 days or 90 days.

This study was performed in compliance with Good Laboratory Practices (GLP) and the OECD Guidelines No. 407 and 408 and was approved by the Institutional Animal Care and Use Committee (IACUC) of Korea Conformity Laboratories.

\section{Clinical observations, body weight, and food consumption}

Detailed clinical observations were made once on all surviving animals before the onset of administration. Functional observations were conducted during the last week of treatment for the 90-day treated study and during the last week of observation for the recovery study. Functional observations were performed within $6 \mathrm{~h}$ after administration. Individual animal weights were recorded at acquisition and grouping, before administration, once weekly during the study, and before necropsy. Food consumption was measured immediately before the first administration and once weekly during the study. To calculate daily food intake, the food ration in each cage was weighed the day before the body weight measurement, and orts (leftover food) were 
measured on the day of the body weight measurement. Food consumption per animal was recalculated according to the average individual consumption $\left(\mathrm{g} \mathrm{rat}^{-1} \mathrm{~d}^{-1}\right)$, and water intake was measured immediately before the first administration and once weekly during the study. The measurement and calculation of the water intake per animal were consistent with those for the food consumption.

\section{Hematology and clinical biochemistry}

All animals were fasted overnight before necropsy, but water was provided ad libitum. At necropsy, the rats were anesthetized with isoflurane. Blood samples were extracted from the abdominal aorta using a syringe and collected in EDTA-K2 tubes (Microtainer ${ }^{\circ}$; Becton, Dickinson, and Company, Franklin Lakes, NJ, USA), $3.2 \%$ sodium citrate tubes (Vacuette ${ }^{\circ}$; Greiner Bio-One, Kremsmünster, Austria), and serum-separating tubes (Insepack $^{\circledR}$; Sekisui Diagnostics, Lexington, MA, USA). In certain cases, blood samples were collected from the jugular vein to measure the methemoglobin concentration within $6 \mathrm{~h}$ after administration on the last day of treatment. For the recovery study, the blood samples were drawn from the abdominal aorta at necropsy and stored in heparin tubes $\left(20-30 \mathrm{IU} \mathrm{mL}^{-1}\right)$. Blood collected in the EDTA-K2 tube was analyzed with a hematology analyzer (Advia 2120; Siemens Limited, Dublin, Ireland). Methemoglobin concentrations were determined with a blood gas analyzer (GEM Premier 4000; Instrumentation Laboratory Company, Bedford, MA, USA). Erythrocytes with Heinz bodies were counted after supravital staining. Blood biochemistry was analyzed with a biochemistry analyzer (Hitachi 7180; Hitachi, Chiyoda, Tokyo, Japan). Serum was isolated and collected by centrifugation in a serum-separating tube at $3000 \mathrm{rpm}$ for $10 \mathrm{~min}$.

\section{Necropsy and histopathology}

After administration, necropsies were conducted on all surviving animals, and complete post-mortem examinations were performed on all organs. All organs were harvested, and some organs were weighed immediately after extraction (Table S9). Excised organs were fixed in 10\% neutral phosphate-buffered formalin. Testes and epididymis were fixed in Bouin's solution, and eyes were fixed in Davidson's solution. Bilateral organs were fixed and organs with macroscopically abnormal lesions were preserved. Thin sections were made from all the preserved organs and tissues of the vehicle control and high-dose groups, mounted on histology slides, and examined histopathologically by hematoxylin and eosin (H\&E) staining.

\section{Statistical analysis}

Statistical differences among the vehicle control and dosing groups were analyzed by parametric or nonparametric multiple comparison methods. Differences were considered statistically significant at $P<0.05$. The incidence rate was represented as a percentage. Statistical analysis was performed with SPSS for Windows v. 12.0 (IBM Corp., Armonk, NY, USA) and in compliance with the standard operating procedures of the testing facility.

\section{Supplementary information}

Supplementary information accompanies this paper at https://doi.org/10. 1186/s12989-020-00350-6.

\begin{abstract}
Additional file 1: Table S1. Urinalysis of male and female rats in the 28-day treatment study. Table S2. Gross findings of male and female rats in the 28-day treatment study. Table S3. Absolute organ weights of rats in 28-day treatment study, mean \pm SD (number of animals). Table S4. Detailed clinical observations of male and female rats in the 90-day treatment study. Table S5. Gross findings of rats in the (A) 90-day treatment and (B) recovery studies. Table S6. Absolute organ weights of rats in 90day treatment study, mean \pm SD (number of animals). Table S7. Absolute organ weight of rats in the recovery study, mean \pm SD (number of animals). Table S8. Group description for the repeated-dose 28-day and 90day oral toxicity studies. Table $\mathbf{S 9}$. List of collected organs
\end{abstract}

\section{Abbreviations}

BUN: Blood urea nitrogen; DLS: Dynamic light scattering; TEM: Transmission electron microscopy; LY: Lymphocyte; LYP: Lymphocyte percentage; MCV: Mean corpuscular volume; PMN: Neutrophil; PMNP: Neutrophil percentage; NOAEL: No observed adverse effect level; $\mathrm{TiO}_{2}$ : Nanoparticles, titanium dioxide nanoparticles

\section{Acknowledgments}

The authors gratefully acknowledge the support of the EU Horizon 2020PATROLS project (grant agreement No. 760813).

\section{Authors' contributions}

TGL and MBH designed the study and collected and analyzed data. MK performed the dispersion of particles and measured the particle size. JHK performed TEM analysis. KSA and KSS managed the animal experiments and prepared the final test reports. HJK and HYP observed the mortalities, clinical signs, functional observation battery, weekly body weights, food and water consumption, and performed ophthalmological examination and urinalysis. SML observed the clinical pathology and necropsy and performed histopathological examination. MBH, KSA, and IYK contributed to the revision and review of the final manuscripts. All authors contributed to the writing of the manuscript and read and approved the final manuscript.

\section{Funding}

This work was supported by the Nano Material Technology Development Program (No. 2016M3A7B6908929) of the National Research Foundation (NRF) funded by the Ministry of Science and ICT.

\section{Availability of data and materials}

The datasets used and/or analyzed during the current study are available from the corresponding author on reasonable request.

\section{Ethics approval and consent to participate}

All experimental procedures followed the OECD Guidelines for the Testing of Chemicals, No. 407 'Repeated Dose 28-day Oral Toxicity Study in Rodents' \& No. 408 'Repeated Dose 90-day Oral Toxicity Study in Rodents' and was approved by the Institutional Animal Care and Use Committee (IACUC) of Korea Conformity Laboratories (approval No.: IA17-00181).

\section{Consent for publication}

Not applicable.

Competing interests

All authors declare that they have no competing interests. 


\section{Author details}

'Center for Nano-Bio Measurement, Industrial Metrology, Korea Research Institute of Standards and Science (KRISS), Yuseong-Gu, Daejeon, Republic of Korea. ${ }^{2}$ Korea Conformity Laboratories (KCL), Yeonsu-Gu, Incheon, Republic of Korea. ${ }^{3}$ Center for Nanocharacterization, Industrial Metrology, Korea Research Institute of Standards and Science (KRISS), Yuseong-Gu, Daejeon, Republic of Korea.

\section{Received: 10 June 2019 Accepted: 11 May 2020}

Published online: 17 July 2020

\section{References}

1. Wolf R, Matz H, Orion E, Lipozencic J. Sunscreens-the ultimate cosmetic Acta Dermatovenerol Croat. 2003;11(3):158-62 https://hrcak.srce.hr/ file/131453\#page $=17$.

2. Kaida T, Kobayashi K, Adachi M, Suzuki F. Optical characteristics of titanium oxide interference film and the film laminated with oxides and their applications for cosmetics. J Cosmet Sci. 2004;55(2):219-20.

3. Warheit DB, Brown SC. What is the impact of surface modifications and particle size on commercial titanium dioxide particle samples? - a review of in vivo pulmonary and oral toxicity studies. Toxicol Lett 2019;302:42-59. https://doi.org/10.1016/j.toxlet.2018.11.008.

4. U.S. Food and Drug Administration. Summary of color additives for use in the United States in foods, drugs, cosmetics, and medical devices. 2017. https://www.fda.gov/Forlndustry/ColorAdditives/ColorAdditivelnventories/ ucm115641.htm

5. Younes M, Aquilina G, Castle L, Engel K-H, Fowler P, Fernandez MJF, et al. Scientific opinion on the proposed amendment of the EU specifications for titanium dioxide (E 171) with respect to the inclusion of additional parameters related to its particle size distribution. EFSA J 2019. https://doi. org/10.2903/j.efsa.2019.5760.

6. Li N, Duan Y, Hong M, Zheng L, Fei M, Zhao X, et al. Spleen injury and apoptotic pathway in mice caused by titanium dioxide nanoparticules. Toxicol Lett 2010;195(2-3):161-168. https:/doi.org/10.1016/j.toxlet.2010.03.1116.

7. Doudi M, Setorki M. Influence of titanium dioxide nanoparticles on oxidative stress and pulmonary dysfunction. Zahedan J Res Med Sci 2015;17(9):e1062. https://doi.org/10.17795/zjrms-1062

8. Pujalté I, Dieme D, Haddad S, Serventi AM, Bouchard M. Toxicokinetics of titanium dioxide (TiO2) nanoparticles after inhalation in rats. Toxicol Lett 2017;265:77-85. https://doi.org/10.1016/j.toxlet.2016.11.014.

9. Wang J, Zhou G, Chen C, Yu H, Wang T, Ma Y, et al. Acute toxicity and biodistribution of different sized titanium dioxide particles in mice after oral administration. Toxicol Lett 2007;168(2):176-185. https://doi.org/10.1016/j. toxlet.2006.12.001

10. Wu J, Liu W, Xue C, Zhou S, Lan F, Bi L, et al. Toxicity and penetration of $\mathrm{TiO} 2$ nanoparticles in hairless mice and porcine skin after subchronic dermal exposure. Toxicol Lett 2009;191(1):1-8. https://doi.org/10.1016/j. toxlet.2009.05.020

11. Shi H, Magaye R, Castranova V, Zhao J. Titanium dioxide nanoparticles: a review of current toxicological data. Part Fibre Toxicol. 2013;10:15. https:// doi.org/10.1186/1743-8977-10-15

12. Lee KP, Trochimowicz HJ, Reinhardt CF. Pulmonary response of rats exposed to titanium dioxide (TiO2) by inhalation for two years. Toxicol Appl Pharmacol 1985; 79(2):179-192. https://doi.org/10.1016/0041-008X(85)90339-4.

13. IARC. Carbon black, titanium dioxide, and talc. IARC Monogr Eval Carcinog Risks Hum. 2010;93:1-413 https://www.ncbi.nlm.nih.gov/books/NBK326521/ pdf/Bookshelf_NBK326521.pdf.

14. MacNicoll A, Kelly M, Aksoy H, Kramer E, Bouwmeester H, Chaudhry Q. A study of the uptake and biodistribution of nano-titanium dioxide using in vitro and in vivo models of oral intake. J Nanopart Res 2015;17:66. https:// doi.org/10.1007/s11051-015-2862-3.

15. Jones K, Morton J, Smith I, Jurkschat K, Harding AH, Evans G. Human in vivo and in vitro studies on gastrointestinal absorption of titanium dioxide nanoparticles. Toxicol Lett 2015;233(2):95-101. https://doi.org/10.1016/j. toxlet.2014.12.005

16. OECD. OECD guidelines for the testing of chemicals, Section 4: Health Effects. Test No. 407: Repeated Dose 28-day Oral Toxicity Study in Rodents: Organisation for Economic Cooperation and Development; 2008. p. 1-13. https://doi.org/10.1787/9789264070684-en.

17. OECD. OECD guidelines for the testing of chemicals, Section 4: Health Effects. Test No. 408: Repeated Dose 90-day Oral Toxicity Study in Rodents:
Organisation for Economic Cooperation and Development; 2018. p. 1-10. https://doi.org/10.1787/9789264070707-en.

18. Joo NY, Lee J, Kim SJ, Hong Sh, Park HM, Yun WS, et al. Preparation of an aqueous suspension of stabilized $\mathrm{TiO} 2$ nanoparticles in primary particle form. J Nanosci Nanotechnol 2013;13(9):6153-6159. https://doi.org/10.1166/ jnn.2013.7637.

19. Taurozzi JS, Hackley VA, Wiesner MR. Preparation of nanoparticle dispersions from powdered material using ultrasonic disruption. NIST Spec Publ. 12001202. 2012. https://doi.org/10.6028/NIST.SP.1200-2.pdf.

20. Taurozzi JS, Hackley VA, Wiesner MR. Preparation of a nanoscale TiO2 aqueous dispersion for toxicological or environmental testing. NIST Spec Publ. 12001203. 2012. https://doi.org/10.6028/NIST.SP.1200-3.pdf.

21. Warheit DB, Hoke RA, Finlay C, Donner EM, Reed KL, Sayes CM. Development of a base set of toxicity tests using ultrafine $\mathrm{TiO} 2$ particles as a component of nanoparticle risk management. Toxicol Lett 2007:171(3):99_ 110. https://doi.org/10.1016/j.toxlet.2007.04.008.

22. Warheit DB, Brown SC, Donner EM. Acute and subchronic oral toxicity studies in rats with nanoscale and pigment grade titanium dioxide particles. Food Chem Toxicol 2015;84:208-224. https://doi.org/10.1016/j.fct.2015.08.026.

23. Cho WS, Kang BC, Lee JK, Jeong J, Che JH, Seok SH. Comparative absorption, distribution, and excretion of titanium dioxide and zinc oxide nanoparticles after repeated oral administration. Part Fibre Toxicol. 2013:10; 9. https://doi.org/10.1186/1743-8977-10-9.

24. Tassinari R, Cubadda F, Moracci G, Aureli F, D'Amato M, Valeri M, et al. Oral, short-term exposure to titanium dioxide nanoparticles in Sprague-Dawley rat: focus on reproductive and endocrine systems and spleen. Nanotoxicology. 2014;8(6):654-662. https://doi.org/10.3109/17435390.2013.822114.

25. Dasal V, Venugopal R, Gaddam AR. Oral toxic exposure of titanium dioxide nanoparticles on serum biochemical changes in adult male Wistar rats. Nanomed J 2015;2(1):46-53. https://doi.org/10.7508/NMJ.2015.01.005.

26. Sang X, Zheng L, Sun Q, Li N, Cui Y, Hu R, et al. The chronic spleen injury of mice following long-term exposure to titanium dioxide nanoparticles. J Biomed Mater Res A 2012;100(4):894-902. https://doi.org/10.1002/jbm.a.34024.

27. Gao G, Ze Y, Li B, Zhao X, Zhang T, Sheng L, et al. Ovarian dysfunction and gene-expressed characteristics of female mice caused by long-term exposure to titanium dioxide nanoparticles. J Hazard Mater 2012;243:19-27. https://doi.org/10.1016/j.jhazmat.2012.08.049.

28. Gao G, Ze Y, Zhao X, Sang X, Zheng L, Ze X, et al. Titanium dioxide nanoparticle-induced testicular damage, spermatogenesis suppression, and gene expression alterations in male mice. J Hazard Mater. 2013;258-259: 133-143. https://doi.org/10.1016/j.jhazmat.2013.04.046.

29. Heringa MB, Peters RJB, Bleys RLAW, van der Lee MK, Tromp PC, van Kesteren PCE, et al. Detection of titanium particles in human liver and spleen and possible health implications. Part Fibre Toxicol 2018;15(1):15. https://doi.org/10.1186/s12989-018-0251-7.

30. Weir A, Westerhoff P, Fabricius L, Hristovski K, von Goetz N. Titanium dioxide nanoparticles in food and personal care products. Environ Sci Technol 2012; 46(4):2242-2250. https://doi.org/10.1021/es204168d.

31. Peters RJ, van Bemmel G, Herrera-Rivera Z, Helsper HP, Marvin HJ, Weigel S, et al. Characterization of titanium dioxide nanoparticles in food products: analytical methods to define nanoparticles. J Agric Food Chem 2014;62(27): 6285-6293. https://doi.org/10.1021/jf5011885.

32. Proquin H, Rodríguez-Ibarra C, Moonen CG, Urrutia Ortega IM, Briedé JJ, de Kok TM, et al. Titanium dioxide food additive (E171) induces ROS formation and genotoxicity: contribution of micro and nano-sized fractions. Mutagenesis. 2017;32(1):139-149. https://doi.org/10.1093/mutage/gew051.

33. Bettini S, Boutet-Robinet E, Cartier C, Coméra C, Gaultier E, Dupuy J, et al. Food-grade $\mathrm{TiO} 2$ impairs intestinal and systemic immune homeostasis, initiates preneoplastic lesions and promotes aberrant crypt development in the rat colon. Sci Rep 2017;7:40373. https://doi.org/10.1038/srep40373.

34. Proquin H, Jetten MJ, Jonkhout MCM, Garduño-Balderas LG, Briedé JJ, de Kok TM, et al. Gene expression profiling in colon of mice exposed to food additive titanium dioxide (E171). Food Chem Toxicol 2018;111:153-165. https://doi.org/10.1016/j.fct.2017.11.011.

\section{Publisher's Note}

Springer Nature remains neutral with regard to jurisdictional claims in published maps and institutional affiliations. 